\title{
Role of magnetic ordering for the design of quinary TWIP-TRIP high entropy alloys
}

\author{
Xiaoxiang Wu $\odot,{ }^{1, *}$ Zhiming Li $\odot,{ }^{1,2, \dagger}$ Ziyuan Rao, ${ }^{1}$ Yuji Ikeda $\odot,{ }^{1}$ Biswanath Dutta $\odot,{ }^{3}$ \\ Fritz Körmann, ${ }^{1,3}$ Jörg Neugebauer, ${ }^{1}$ and Dierk Raabe ${ }^{1}$ \\ ${ }^{1}$ Max-Planck-Institut für Eisenforschung, Max-Planck-Str. 1, 40237 Düsseldorf, Germany \\ ${ }^{2}$ School of Materials Science and Engineering, Central South University, Changsha 410083, China \\ ${ }^{3}$ Materials Science and Engineering, Delft University of Technology, 2628 CD, Delft, The Netherlands
}

(Received 13 December 2019; accepted 11 February 2020; published 3 March 2020)

\begin{abstract}
We reveal the impact of magnetic ordering on stacking fault energy (SFE) and its influence on the deformation mechanisms and mechanical properties in a class of nonequiatomic quinary Mn-containing compositional complex alloys or high entropy alloys (HEAs). By combining $a b$ initio simulation and experimental validation, we demonstrate magnetic ordering as an important factor in the activation and transition of deformation modes from planar dislocation slip to TWIP (twinning-induced plasticity) and/or TRIP (transformation-induced plasticity). A wide compositional space of $\mathrm{Cr}_{20} \mathrm{Mn}_{x} \mathrm{Fe}_{y} \mathrm{Co}_{20} \mathrm{Ni}_{z}(x+y+z=60$, at. \%) was probed by density-functional theory calculations to search for potential alloys displaying the TWIP/TRIP effects. Three selected promising HEA compositions with varying Mn concentrations were metallurgically synthesized, processed, and probed for microstructure, deformation mechanism, and mechanical property evaluation. The differences in the deformation modes of the probed HEAs are interpreted in terms of the computed SFEs and their dependence on the predicted magnetic state, as revealed by ab initio calculations and validated by explicit magnetic measurements. It is found that the Mn content plays a key role in the stabilization of antiferromagnetic configurations which strongly impact the SFEs and eventually lead to the prevalent deformation behavior.
\end{abstract}

DOI: 10.1103/PhysRevMaterials.4.033601

\section{INTRODUCTION}

Designing structural alloys with excellent mechanical properties, e.g., with a good combination of strength and ductility is one of the ultimate objectives for materials scientist. The stacking fault energy (SFE) acts as one of the most important parameters in this aspect [1-5]. For example, to fabricate steels with high strength and ductility synergy, various amounts of $\mathrm{Mn}, \mathrm{Al}$, and $\mathrm{Si}$ are often alloyed to tune the SFE and activate transformation-induced plasticity (TRIP) and twinning-induced plasticity (TWIP) mechanisms [4-7]. This is due to the fact that dislocation behavior is significantly influenced by SFE. When the SFE is above $45 \mathrm{~mJ} / \mathrm{m}^{2}$, full dislocations do not split into partials and dislocation gliding is the dominant deformation mechanism $[8,9]$. When the SFE decreases to the range of $20-40 \mathrm{~mJ} / \mathrm{m}^{2}$, planar slip and TWIP prevail. Further SFE reduction to $20 \mathrm{~mJ} / \mathrm{m}^{2}$ and below generally leads to a TRIP effect in such steels where hexagonal, tetragonal, or body-centered cubic product phases can emerge, through the Olsen-Cohen mechanism [10,11]. The formation of deformation twins is associated with the passage of Shockley partial dislocations on every $\{111\}$ plane in

\footnotetext{
*x.wu@mpie.de

†zhiming.li@mpie.de
}

Published by the American Physical Society under the terms of the Creative Commons Attribution 4.0 International license. Further distribution of this work must maintain attribution to the author(s) and the published article's title, journal citation, and DOI. Open access publication funded by the Max Planck Society. face-centered cubic (fcc) materials, while the generation of a hexagonal close-packed (hcp) phase is induced by the passage of Shockley partials on every second $\{111\}$ plane [12-14]. The similar strengthening strategies have been applied to high entropy alloys (HEAs) or compositionally complex alloys (CCAs) $[2,4,12,15-17]$. HEAs and CCAs allow exploration of vast compositional space by combining multiprincipal elements, introducing massive solid solution strengthening [18-21]. Pioneering work has shown that equiatomic quinary HEAs are promising materials with excellent properties such as good strength-ductility combination and fracture toughness at ambient [18,22] and cryogenic temperatures [23,24], as well as high resistance to hydrogen embrittlement [25-27].

The SFE is known to be sensitive to both temperature and composition, e.g., in Refs. [6,28,29]. However, the influence of magnetism, for example, magnetic ordering upon SFE and correspondingly on deformation mechanisms are less commonly investigated, and yet of significant importance. A recent study by Niu et al. [30] reveals a magnetically driven phase transformation strengthening effect in a $\mathrm{CrCoNi}$ HEA. In their work, the authors exclusively analyzed the magnetic effect upon mechanical properties in CrCoNi HEAs and pointed out $\mathrm{Mn}$ as a magnetically frustrated element. However, how exactly Mn affects the mechanical properties in the aspect of magnetic ordering is still unclear. It is also not so clear whether the effect of magnetism is only seen in the ternary HEAs with TRIP effect or it is universal and applies also to other TRIP quinary HEAs. Thus, it is of high interest and significance to explore the effect of magnetism upon quinary Mn-containing HEAs. Valence electron concentration (VEC) values are also known to relate to the phase 
stability of HEAs [31-33]. For instance, recently Fang et al. [33] observed that when the VEC value fall into a certain rage, a change of the deformation mechanism is expected for $\mathrm{Cr}_{25} \mathrm{Fe}_{40-x} \mathrm{Co}_{35} \mathrm{Ni}_{x}(x=0-15$ at. \%) HEAs.

$A b$ initio calculations have been successfully utilized to estimate the SFEs of various HEAs. To take the effect of magnetic ordering and VEC upon SFE into consideration, in the present study we further employ $a b$ initio calculations to efficiently screen for quinary compositions based on the SFEs [1,30,34-41] and design nonequiatomic HEAs with TRIP and/or TWIP. We first computationally screen for SFEs of alloys in the quasiternary $\mathrm{Cr}_{20} \mathrm{Mn}_{x} \mathrm{Fe}_{y} \mathrm{Co}_{20} \mathrm{Ni}_{z}(x+y+z=$ 60 , at. \%) compositional space, where we take the effect of magnetic ordering upon SFE into consideration. Based on an initial set of calculations, we select three nonequiatomic quinary HEAs with relatively low SFEs and then systematically analyze their mechanical behavior and deformation mechanisms in experiments. While alloy design is normally time-consuming and costly, the present combinatorial approach of simulation and experiments demonstrates a pathway for efficiently and economically screening materials with targeted properties, and reveals that the magnetic ordering tendency is a critical factor to be considered. This kind of alloy design approach is not limited to CCA/HEAs, but can also be applied to other structural alloys.

\section{METHODS}

\section{A. Ab initio calculations}

Electronic structure calculations were performed employing the exact-muffin-tin-orbital (EMTO) method [42-46] in combination with the full-charge-density method $[47,48]$ within the framework of density-functional theory. The chemical disorder was modeled using the coherent-potential approximation (CPA) [49-51]. The charges and the energies were calculated within the generalized-gradient approximation of the Perdew-Burke-Ernzerhof form [52]. The Brillouin zones were sampled by more than $12500 / n k$-points per unit cell, where $n$ indicates the number of atoms in the unit cell.

To illustrate the impact of magnetic ordering, we considered both the paramagnetic (PM) and ordered magnetic states. Both experiments [53] and previous $a b$ initio calculations $[54,55]$ reported that the equiatomic $\mathrm{CrMnFeCoNi}$ Cantor alloy is in the PM state at room temperature. In the present study, we approximated the PM state by the disordered local moment model $[46,56,57]$ combined with the CPA. In a previous EMTO-CPA study [55], it was found that if no sublattice magnetic ordering is considered, a magnetic state where the magnetic moments of $\mathrm{Cr}$ and $\mathrm{Mn}$ are aligned oppositely to those of $\mathrm{Fe}, \mathrm{Co}, \mathrm{Ni}$ is energetically the most stable collinear magnetic state in the fcc phase. Given the fact that in particular Fe and $\mathrm{Mn}$ in elemental bulk fcc phases are prone to different kinds of antiferromagnetic ordering, we employ in the present study an extended set of calculations where we specifically screen for antiferromagnetic states. For a wide range of compositions including equiatomic $\mathrm{CrMnFeCoNi}$, an antiferromagnetically ( $\{100\}$ layered) ordered state is found to be lower in energy (up to $\sim 23 \mathrm{meV} /$ atom depending on composition) as compared to the above discussed and previously considered [54,55,58] magnetic state with Mn and $\mathrm{Cr}$ moments antiferromagnetically aligned relative to $\mathrm{Fe}, \mathrm{Co}$, and $\mathrm{Ni}$ moments [55] (a detailed analysis on the impact of magnetism on other properties will be given elsewhere $[59,60])$. In the present study, we therefore focused on the antiferromagnetic (AFM) state as an alternative representative ordered magnetic state of the fcc phase. For the hcp phase, similarly, \{0001\}-layer AFM state was considered as a representative ordered magnetic state.

The intrinsic SFEs were computed based on the first-order axial Ising model (AIM1) [61,62] as

$$
\gamma_{\mathrm{ISF}} \approx \frac{2\left(E_{\mathrm{hcp}}-E_{\mathrm{fcc}}\right)}{A},
$$

where $A$ denotes the area per atom, and $E_{\alpha}$ denotes the energy per atom of the phase $\alpha$. We confirmed that the second-order axial Ising model (AIM2) [61] shows essentially the same trend as that of the AIM1 for the PM state. The volumes of the fcc phase were determined by fitting the energy-volume relations to the third-order Birch-Murnaghan equation of state $[63,64]$, and the intrinsic SFE was computed at the determined fcc equilibrium volume for each composition (see Supplemental Material [65] for the results at the experimental lattice constant of the Cantor alloy). For the hcp phase, the ideal $c / a$ ratio ( $\sqrt{8 / 3} \approx 1.633$ ) was employed, as recent experiments $[66,67]$ also revealed that $\mathrm{CrMnFeCoNi}$ in the hcp phase shows a $c / a$ ratio close to the ideal one at ambient conditions. Internal atomic positions were fixed to keep the rigid-sphere packing.

The magnetic critical temperature $T_{c}$ was computed based on the mean-field approximation $[40,54,68]$ as

$$
k_{B} T_{c}=\frac{2}{3}\left(E_{\mathrm{PM}}-E_{\mathrm{AFM}}\right),
$$

where $k_{\mathrm{B}}$ is the Boltzmann constant, and $E_{\alpha}$ is the energy of the magnetic phase $\alpha$ per atom at the volume in the AFM fcc phase. Here the AFM phase was set as the reference of the magnetically ordered one. Note that mean-field approximation often tends to overestimate the magnetic critical temperature.

The VEC of a HEA was computed as the average of the VEC of the constituent elements weighted by their concentrations in atomic percent, where the $\mathrm{VEC}$ of $\mathrm{Cr}, \mathrm{Mn}, \mathrm{Fe}, \mathrm{Co}$, and Ni were chosen as $6,7,8,9$, and 10 , respectively.

\section{B. Alloy preparation}

The three alloys selected from the $a b$ initio calculations were cast using a vacuum induction furnace. Wet chemical analysis was employed to measure the chemical composition for confirming the concentrations of the elements after casting. The measured compositions are shown in Table I. For accuracy, the compositions were measured from three different parts of the casting alloys. For removing cast defects such as void and pores, as-cast alloys were hot rolled at $950{ }^{\circ} \mathrm{C}$ for a thickness reduction of $50 \%$. Subsequent homogenization was carried out at $1200{ }^{\circ} \mathrm{C}$ for $2 \mathrm{~h}$ in Ar atmosphere followed by quenching in water. 
TABLE I. Compositions of the three alloys under investigation in as-cast state using wet chemical analysis (at. \%).

\begin{tabular}{|c|c|c|c|c|c|c|}
\hline & Nominal & $\mathrm{Cr}$ & $\mathrm{Mn}$ & $\mathrm{Fe}$ & Co & $\mathrm{Ni}$ \\
\hline Alloy I & $\mathrm{Cr}_{20} \mathrm{Mn}_{24} \mathrm{Fe}_{30} \mathrm{Co}_{20} \mathrm{Ni}_{6}$ & $19.93 \pm 0.12$ & $23.81 \pm 0.22$ & $30.39 \pm 0.15$ & $19.87 \pm 0.14$ & $5.99 \pm 0.03$ \\
\hline Alloy II & $\mathrm{Cr}_{20} \mathrm{Mn}_{30} \mathrm{Fe}_{24} \mathrm{Co}_{20} \mathrm{Ni}_{6}$ & $19.91 \pm 0.11$ & $29.66 \pm 0.21$ & $24.51 \pm 0.13$ & $19.94 \pm 0.12$ & $5.97 \pm 0.04$ \\
\hline Alloy III & $\mathrm{Cr}_{20} \mathrm{Mn}_{15} \mathrm{Fe}_{34} \mathrm{Co}_{20} \mathrm{Ni}_{11}$ & $20.33 \pm 0.12$ & $15.35 \pm 0.21$ & $32.36 \pm 0.11$ & $20.61 \pm 0.12$ & $11.35 \pm 0.03$ \\
\hline
\end{tabular}

\section{Magnetic properties measurement}

Rectangular-shaped $3 \times 3 \times 1-\mathrm{mm}^{3}$ samples were used to measure temperature dependence of magnetization $M(T)_{\mathrm{H}}$ of the alloys after homogenization, using a Quantum Design Physical Properties Measurement System (PPMS 9) equipped with a standard vibrating sample magnetometry option. The $M(T)_{\mathrm{H}}$ dependence were measured at $0.3,0.4$, and $0.5 \mathrm{~T}$ in a temperature range from 5 to $300 \mathrm{~K}$ with zero-field cooling. The temperature-sweeping rate was $20 \mathrm{~K} / \mathrm{min}$. Hysteresis

(a) $\triangle$ SFE in the paramagnetic (PM) state

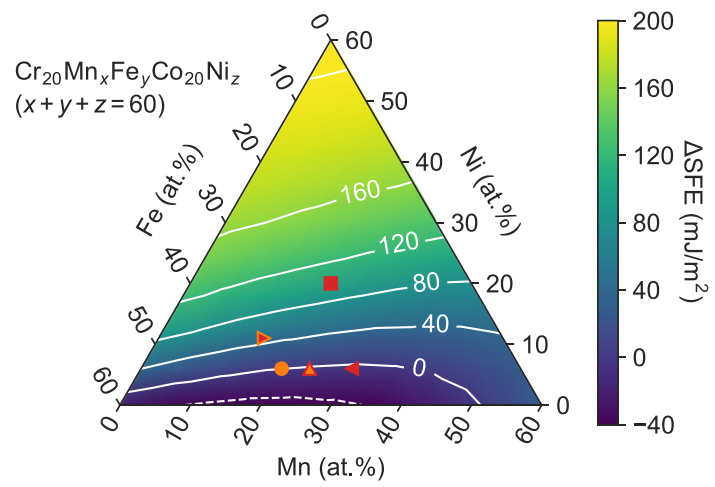

(c) Magnetic critical temperature $T_{c}$ of the AFM state

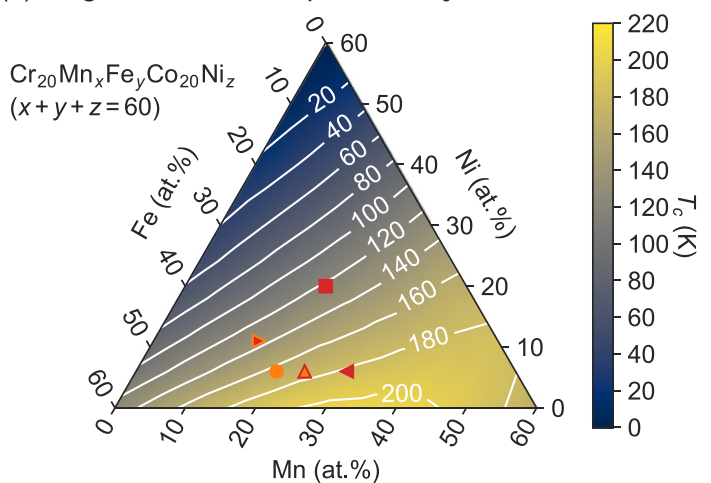

loops $M(H)_{\mathrm{T}}$ were taken at $5 \mathrm{~K}$ in an external magnetic field of $\pm 5 \mathrm{~T}$. The magnetic-field sweeping rate was $50 \mathrm{Oe} / \mathrm{s}$.

\section{Mechanical testing}

For tensile testing, dog-bone shaped specimens $(1 \mathrm{~mm}$ in thickness) were cut using electrical discharge machining. The tensile specimens have a total length of $32 \mathrm{~mm}$, and the gauge area is $10 \mathrm{~mm}$ by length and $2.5 \mathrm{~mm}$ by width. Tensile testing was conducted at room temperature at a strain rate of

(b) $\triangle \mathrm{SFE}$ in the antiferromagnetic (AFM) state

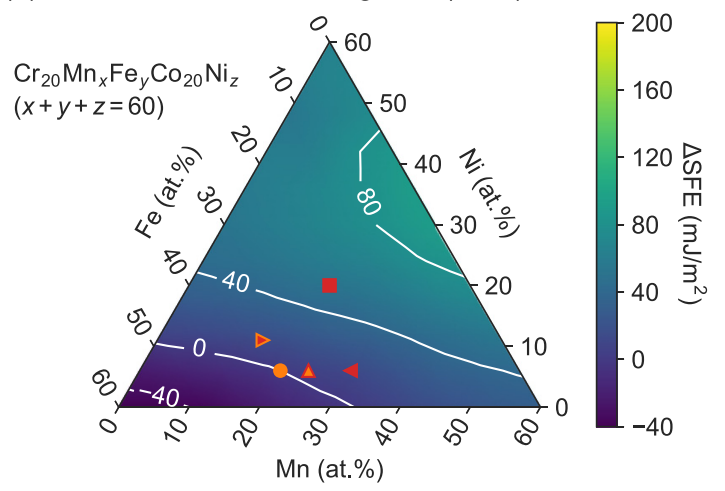

(d) Valence electron concentration (VEC)

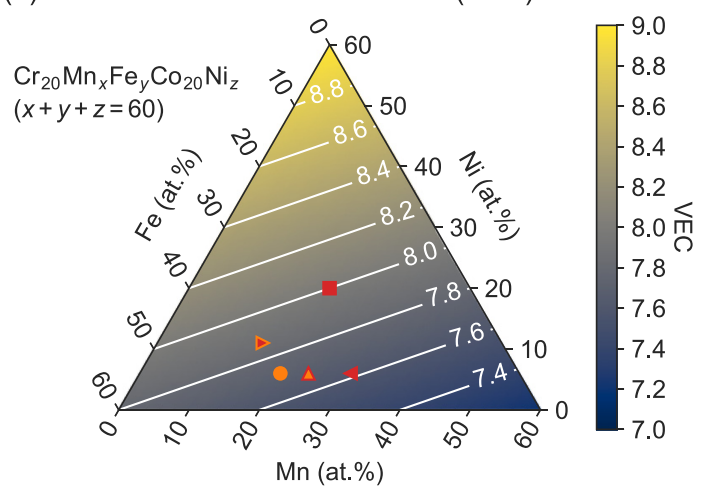

$\Delta \mathrm{Cr}_{20} \mathrm{Mn}_{24} \mathrm{Fe}_{30} \mathrm{Co}_{20} \mathrm{Ni}_{6}$ (TRIP + TWIP): alloy I

$4 \mathrm{Cr}_{20} \mathrm{Mn}_{30} \mathrm{Fe}_{24} \mathrm{Co}_{20} \mathrm{Ni}_{6}$ (TWIP): alloy II

- $\mathrm{Cr}_{20} \mathrm{Mn}_{15} \mathrm{Fe}_{34} \mathrm{Co}_{20} \mathrm{Ni}_{11}$ (TWIP + TRIP): alloy III

- $\mathrm{Cr}_{20} \mathrm{Mn}_{20} \mathrm{Fe}_{20} \mathrm{Co}_{20} \mathrm{Ni}_{20}$ (TWIP)

- $\mathrm{Cr}_{20} \mathrm{Mn}_{20} \mathrm{Fe}_{34} \mathrm{Co}_{20} \mathrm{Ni}_{6}$ (TRIP)

FIG. 1. (a), (b) Difference of the SFEs of quinary $\mathrm{Cr}_{20} \mathrm{Mn}_{x} \mathrm{Fe}_{y} \mathrm{Co}_{20} \mathrm{Ni}_{z}(x+y+z=60$, at. \%) CCAs compared to the reference alloy $\mathrm{Cr}_{20} \mathrm{Mn}_{20} \mathrm{Fe}_{34} \mathrm{Co}_{20} \mathrm{Ni}_{6}$ in the (a) PM and in the (b) AFM states obtained from ab initio calculations. (c) Magnetic critical temperatures of the AFM state obtained from $a b$ initio calculations. (d) Valence electron concentration (VEC) distribution. Triangle symbols show the compositions investigated in the present experiments. Two reference alloys, namely, the equiatomic Cantor alloy (square) and $\mathrm{Cr}_{20} \mathrm{Mn}_{20} \mathrm{Fe}_{34} \mathrm{Co}_{20} \mathrm{Ni}_{6}(\mathrm{circle})$, which is known to show DP-TRIP [1], are also shown. The colors of the symbols show the dominant deformation behavior of the corresponding compositions; orange and red are for TRIP and TWIP, respectively. Visualization is performed using the MPLTERN code [70] in combination with MATPLOTLIB [71]. 

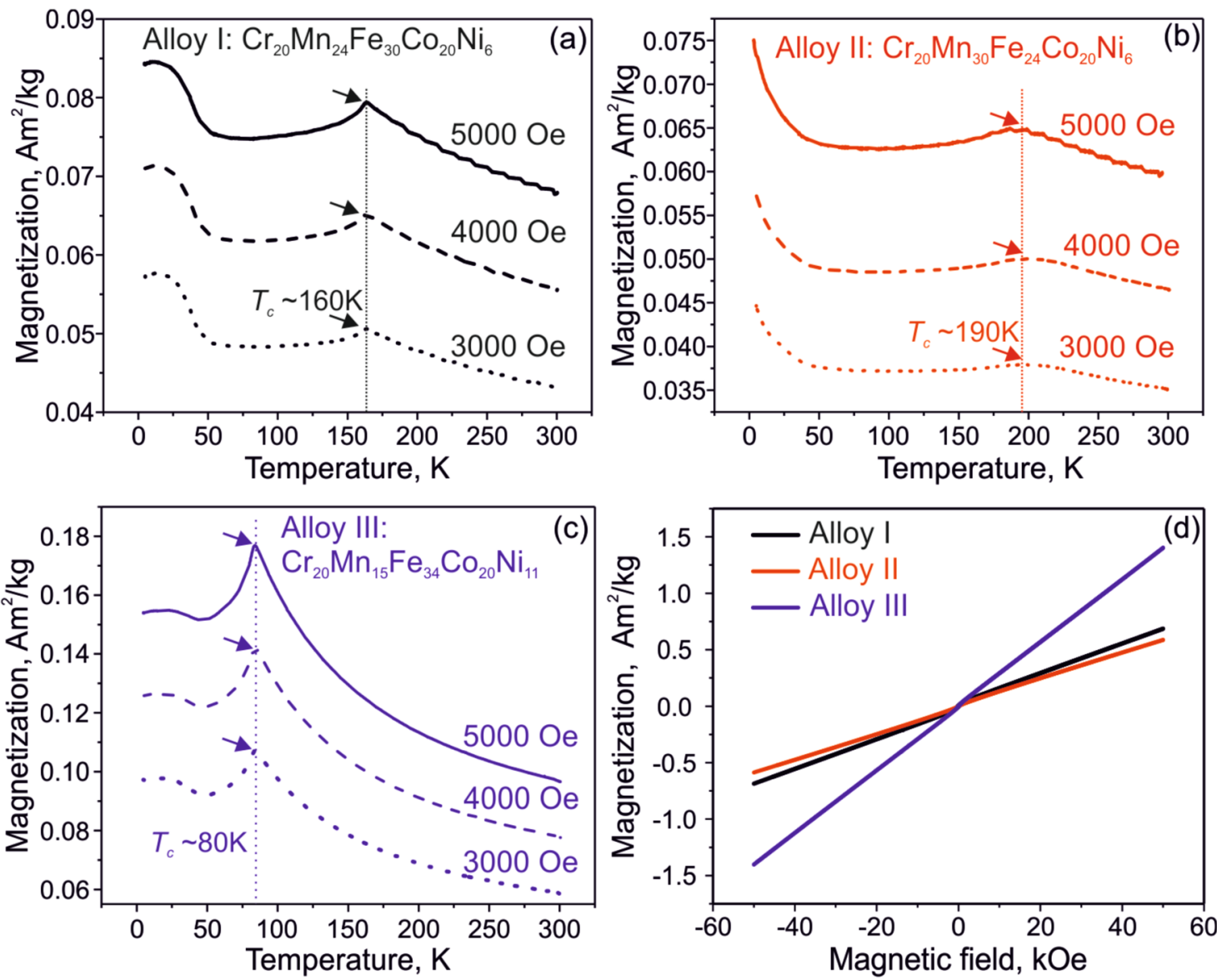

FIG. 2. Temperature dependence of magnetization behavior from 5 to $300 \mathrm{~K}$ for the three alloys under investigation. (a) Alloy I: $\mathrm{Cr}_{20} \mathrm{Mn}_{24} \mathrm{Fe}_{30} \mathrm{Co}_{20} \mathrm{Ni}_{6}$ (at. \%), where the transition temperature is around $160 \mathrm{~K}$; (b) Alloy II: $\mathrm{Cr}_{20} \mathrm{Mn}_{30} \mathrm{Fe}_{24} \mathrm{Co}_{20} \mathrm{Ni}_{6}($ at. $\%$ ), where the transition temperature is around $190 \mathrm{~K}$; (c) Alloy III: $\mathrm{Cr}_{20} \mathrm{Mn}_{15} \mathrm{Fe}_{34} \mathrm{Co}_{20} \mathrm{Ni}_{11}$ (at. \%), where the transition temperature is around $80 \mathrm{~K}$. (d) Hysteresis loops investigated up to $0.5 \mathrm{~T}$ at $5 \mathrm{~K}$ for alloys I to III.

$1.0 \times 10^{-3} \mathrm{~s}^{-1}$ using a Kammrath \& Weiss tensile device. For a precise determination of local strain evolution, we used digital image correlation (DIC) method with the ARAMIS software (GOM GmbH).

\section{E. Microstructural characterization}

Initial phase identification and lattice parameter determination were conducted using $\mathrm{x}$-ray diffraction (XRD). XRD measurements were carried out using $X$-ray equipment ISO-DEBYEFLEX 3003 with a cobalt source $\left(\mathrm{CoK}_{\alpha 1}, \lambda=\right.$ $1.788965 \AA$ ) operated at $40 \mathrm{kV}$ and $30 \mathrm{~mA}$. The $2 \theta$ range for XRD measurement is $20-130^{\circ}$ with a scan step of $0.03^{\circ}$ and counting time of $20 \mathrm{~s} / \mathrm{step}$. The lattice constants were analyzed by Bruker TOPAS version 5.0 using the fundamental parameter fit method.

Multiple techniques were employed to characterize the microstructure evolution. A Zeiss-Crossbeam XB 1540 focused ion beam scanning electron microscope (FIB-SEM) was utilized for electron backscattered diffraction (EBSD) analysis, using a parameter of $15 \mathrm{kV}$ and a step size of $80 \mathrm{~nm}$. Electron channeling contrast (ECC) imaging was performed with a Zeiss-Merlin instrument. Samples for ECC imaging and EBSD were firstly ground using silicon carbide paper, followed by a 3- $\mu$ m diamond suspension polishing. To remove the deformation layer introduced by mechanical grinding, fine polishing was carried out for about $1 \mathrm{~h}$ using oxide suspension (OPS) with silica particle size around $50 \mathrm{~nm}$. To further reveal the detailed microstructures, we conducted transmission electron microscopy (TEM) analysis, using an image-corrected FEI Titan Themis $80-300$ operated in $300 \mathrm{kV}$. TEM foils were prepared by mechanical grinding to a thickness around $100 \mu \mathrm{m}$ followed by electropolishing, using 5\% perchloric acid in acetic acid at a temperature of $17{ }^{\circ} \mathrm{C}$. A site-specific focused ion beam lift-out procedure was also adapted using a dual-beam FIB instrument (FEI Helios Nanolab 600i).

\section{RESULTS}

\section{A. Effect of magnetism upon SFEs}

We first perform a compositional screening of potential TWIP/TRIP HEAs by utilizing ab initio calculations to identify and select promising alloys for further experimental analysis. We note that previous $a b$ initio studies reported that the absolute value of the SFE is affected by finitetemperature excitations such as lattice vibrations $[1,30,36]$ and magnetic fluctuations [1,35,69]. In Ref. [1], it has, however, also been demonstrated that for $\mathrm{Cr}_{20} \mathrm{Mn}_{20} \mathrm{Fe}_{x} \mathrm{Co}_{20} \mathrm{Ni}_{y}$ 

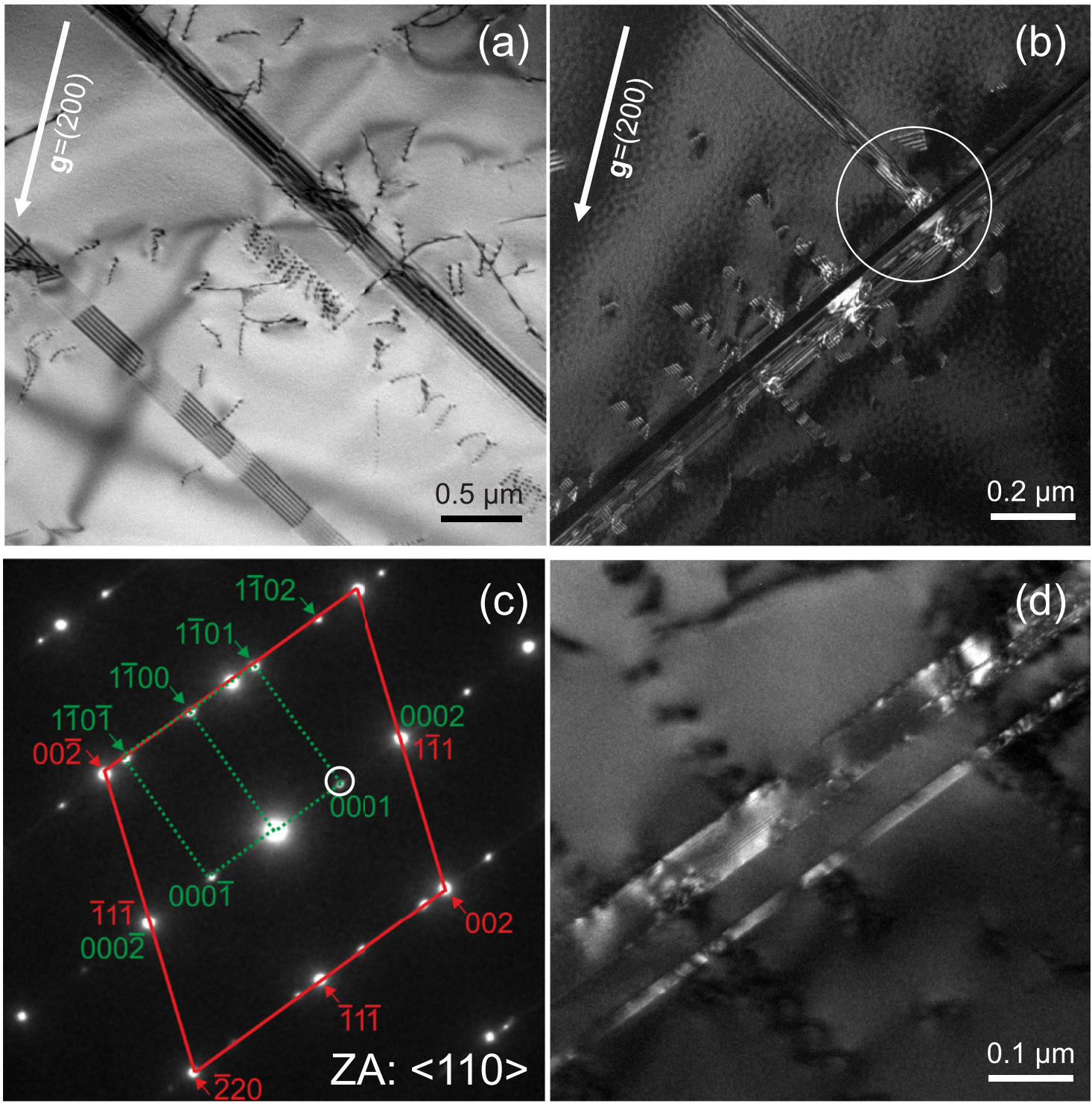

FIG. 3. (a) TEM BF overview showing dislocation arrays and deformation twins for alloy $\mathrm{I}\left(\mathrm{Cr}_{20} \mathrm{Mn}_{24} \mathrm{Fe}_{30} \mathrm{Co}_{20} \mathrm{Ni}_{6}\right.$, at. \%) at a local strain of $\sim 20 \%$. (b) TEM WBDF showing arrays of dislocations, and the white circle is for diffraction pattern in (c). (c) Diffraction pattern showing the presence of hcp and fcc phase. (d) Dark-field image from the (0001) spot highlighting the one hcp phase.

$(x+y=40$, at. \% $)$ the chemical trends, i.e., the variation of the SFE with chemical compositions, were hardly affected by these contributions. To allow a computationally efficient compositional screening, we therefore limit the discussion to different magnetic configurations and do not explicitly include finite temperature.

Figures 1(a) and 1(b) show the computed SFEs for the nonequiatomic quinary alloy system $\mathrm{Cr}_{20} \mathrm{Mn}_{x} \mathrm{Fe}_{y} \mathrm{Co}_{20} \mathrm{Ni}_{z}$ $(x+y+z=60$, at. \%) in the PM [Fig. 1(a)] and AFM [Fig. 1(b)] states. Here, the quinary $\mathrm{Cr}_{20} \mathrm{Mn}_{20} \mathrm{Fe}_{34} \mathrm{Co}_{20} \mathrm{Ni}_{6}$ HEA, which is known to show TRIP in experiments [1], is set as the reference (i.e., $\triangle \mathrm{SFE}$ is set to zero). The magnetic ordering is found to largely alter the compositional dependence of the SFE. In the magnetically disordered PM state [Fig. 1(a)], the Ni content affects the SFE most significantly, while the SFE depends to a much lesser extent on the Mn and the Fe contents. In the magnetically ordered AFM state [Fig. 1(b)], in contrast, contents of Mn and Fe substantially affect the SFE, and hence the compositional dependence of the SFE is more complex than for the PM state. In order to estimate at which temperatures magnetically ordered AFM states become relevant, we show in Fig. 1(c) the computed magnetic critical temperatures $T_{\mathrm{c}}$ employing Eq. (2) by using the energies of the PM and AFM states. Particularly around 5 at. $\%$ of $\mathrm{Ni}$, alloys with increased Mn content show higher $T_{\text {c }}$. This finding implies that Mn stabilizes the AFM state and hence that the AFM state is more appropriate for Mn-rich alloys to predict alloy properties at ambient temperatures. Figure 1(d) shows the VEC of $\mathrm{Cr}_{20} \mathrm{Mn}_{x} \mathrm{Fe}_{y} \mathrm{Co}_{20} \mathrm{Ni}_{z}(x+y+$ $z=60$, at. \%). In this compositional space, VEC is higher in Ni-rich HEAs while lower in Mn-rich HEAs which is due to the higher VEC of Ni than Mn.

The SFE is empirically known to correlate with the deformation behavior of several fcc alloys [15,72-75], and the present $a b$ initio calculations elucidate that magnetic ordering largely affects the compositional dependence of the SFE. 

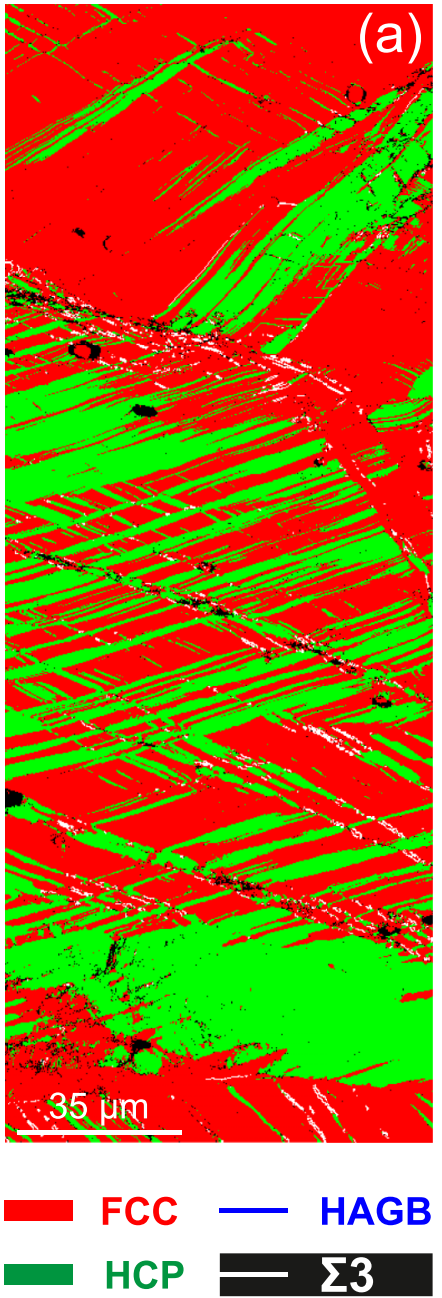
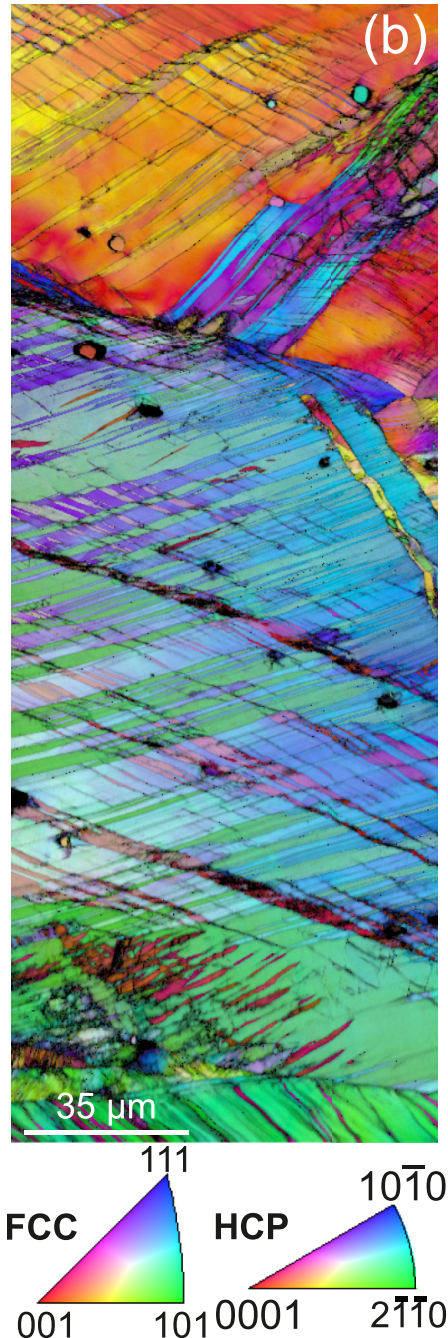
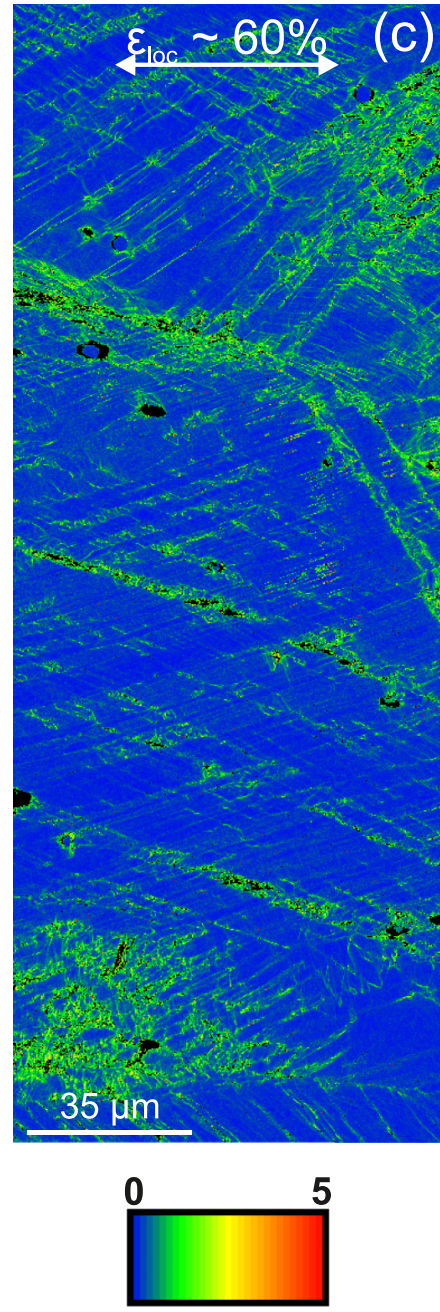
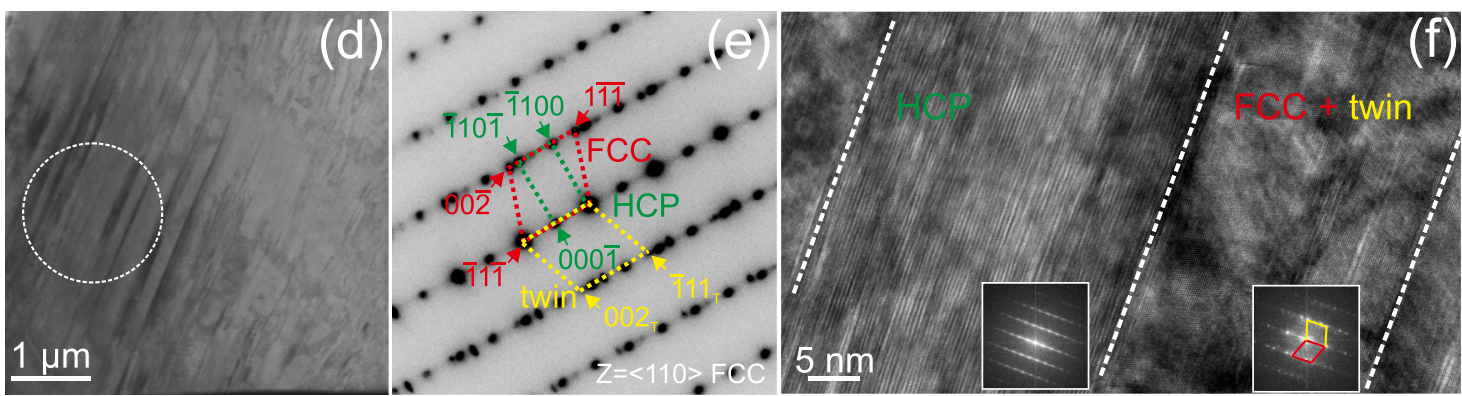

FIG. 4. EBSD and ECCI analysis of alloy $\mathrm{I}\left(\mathrm{Cr}_{20} \mathrm{Mn}_{24} \mathrm{Fe}_{30} \mathrm{Co}_{20} \mathrm{Ni}_{6}\right)$ at a local strain of $60 \%$. (a) Phase map showing the deformed area with a high density of hcp phase (colored in green) and limited twinning (colored in white). (b) Inverse pole figure (IPF) overlapped with image quality (IQ) figure, indicating different orientation of the grains in the investigated region. (c) First-neighbor KAM figure. (d) TEM lamella overview from the same region as in EBSD. (e) Diffraction pattern from the dashed region in (d), showing the coexistence of hcp and deformation twins. (f) High-resolution TEM showing the hcp region and the nanotwins embedded in fcc matrix.

To reveal further the effect of magnetic ordering upon the deformation behavior of the HEAs in detail, we selected the following three compositions and carried out intensive experimental investigation. Alloy I $\left(\mathrm{Cr}_{20} \mathrm{Mn}_{24} \mathrm{Fe}_{30} \mathrm{Co}_{20} \mathrm{Ni}_{6}\right)$ shows the SFE close to that of the reference material both in the PM and in the AFM states. The SFE of the alloy II $\left(\mathrm{Cr}_{20} \mathrm{Mn}_{30} \mathrm{Fe}_{24} \mathrm{Co}_{20} \mathrm{Ni}_{6}\right)$ is close to the reference one in the PM state but not in the AFM state. The SFE of the alloy III $\left(\mathrm{Cr}_{20} \mathrm{Mn}_{15} \mathrm{Fe}_{34} \mathrm{Co}_{20} \mathrm{Ni}_{11}\right)$ is slightly higher than the SFE of the reference alloy both in the PM and in the AFM states, but still lower than the SFE of the Cantor alloy.

The change of magnetic ordering is manifested in critical temperature $T_{c}$. We therefore carried out magnetic measurements to determine $T_{c}$ for the three alloys. The magnetization variation with temperature is shown in Fig. 2 for the alloys I to III for a temperature range of 5-300 K. Figure 2(a) shows that the magnetic transition temperature for alloy I is around $160 \mathrm{~K}$ independent of the magnetic field, while for alloy II, as shown 

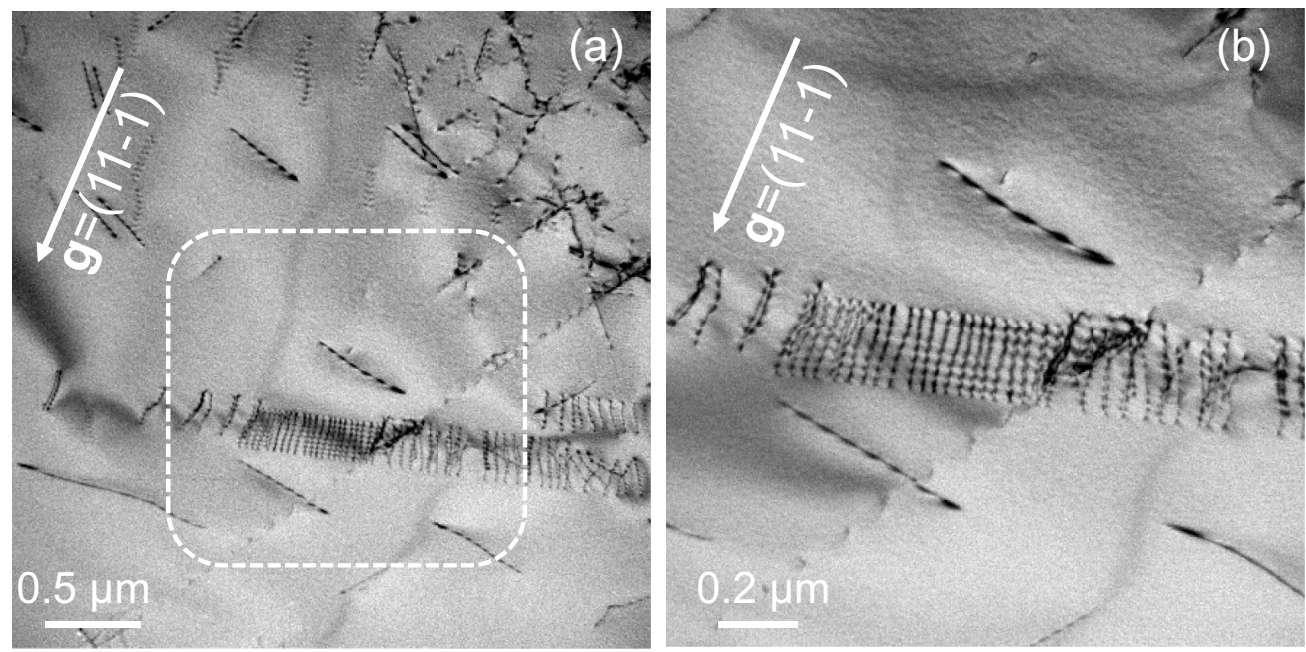

FIG. 5. TEM overview for alloy II $\left(\mathrm{Cr}_{20} \mathrm{Mn}_{30} \mathrm{Fe}_{24} \mathrm{Co}_{20} \mathrm{Ni}_{6}\right)$ at a local strain of 20\%. (a) TEM overview showing dislocation arrays and dislocation pairs. (b) Close-up of the region highlighted from (a), indicating clear planar slip character in alloy II.

in Fig. 2(b), the critical temperature is shifted to nearly $190 \mathrm{~K}$. Alloy III is shown to have the lowest transition temperature at $\sim 80 \mathrm{~K}$ [Fig. 2(c)]. Figure 2(d) presents the hysteresis loops for the three alloys at $5 \mathrm{~K}$. The $M-H$ loops for all the alloys at low temperature exhibit typical antiferromagnetlike behavior, which confirms the AFM ground in this case. The experimentally observed trends of the magnetic state and magnetic transition temperatures for all three alloys are hence consistent with the predicted ones shown in Fig. 1(c) obtained by the $a b$ initio calculations. The hysteresis loops in Fig. 2(d) also show the higher Mn contents lead to a lower magnetization value, thereby confirming the dominant role of $\mathrm{Mn}$ in stabilizing the AFM state.

\section{B. Deformation mechanisms: TWIP vs TRIP}

The deformation mechanisms of the three alloys under investigation are further investigated after DIC-assisted tensile testing. The initial microstructures are shown in Supplemental Material, Fig. S2 [65]. Both EBSD and XRD results show that alloy I has a dual hcp/fcc phase but maintains a majority of fcc phase, while alloys II and III are single fcc structure. The EDS mapping in Fig. S3 [65] indicates that all elements in three alloys are homogeneously distributed, with some Mn or Cr-enriched inclusions randomly distributed in the materials. The tensile behavior in Fig. S4 [65] reveals an enhanced strength and work hardening of alloys I and II compared to alloy III and the Cantor alloy. To rationalize the tensile behavior and understand the deformation mechanisms, we systematically elucidate the microstructures evolution of the three alloys under investigation at different local strains.

\section{Alloy I $\left(\mathrm{Cr}_{20} \mathrm{Mn}_{24} \mathrm{Fe}_{30} \mathrm{Co}_{20} \mathrm{Ni}_{6}\right)$}

In Fig. 3, a conventional TEM micrograph for alloy I shows the early stage microstructure at a local strain of $\sim 20 \%$, under a $\mathbf{g}$ condition of (200). We can see clearly two sets of planar defects characterized by the fringe contrast. The extended planar faults on the lower left part of Fig. 3(a) show the similar contrast of deformation twins characterized by the period contrast of the partial dislocations [7,76-79]. However, due to the limitation of the tilt angle during the TEM experiment, no diffraction pattern can be obtained for final confirmation. The TEM weak-beam dark-field (WBDF) image in Fig. 3(b) shows another example of propagating dislocation arrays by utilizing the same imaging condition as in Fig. 3(a), and the white circle marks the region for diffraction pattern (DP) in Fig. 3(c). The DP in Fig. 3(c) shows clearly the coexistence of fcc and hcp phases with an orientation relationship of $(1 \overline{1} 1)_{\mathrm{fcc}}\left\|(0002)_{\mathrm{hcp}} /[110]_{\mathrm{fcc}}\right\|[11 \overline{2} 0]_{\mathrm{hcp}}$. Using the (0001) reflection in DP for dark-field imaging, we can highlight the hop phase in this region, as shown in Fig. 3(d). The planar dislocations and the early occurrence of deformation twins/hep phase indicate also a low SFE for alloy I.

With an increase of the local strain to $60 \%$, fcc to hcp phase transformation is clearly observed, and it is obvious hep phase prevails. Figure 4 shows a representative EBSD map along with TEM micrographs from the same region. The phase map in Fig. 4(a) clearly shows a high volume fraction ( $\sim 36$ vol.\%) of hcp phase induced by tensile deformation. The white lines indicate $\Sigma 3$ deformation twins in the fcc matrix phase, which evidences the coexistence of TRIP and TWIP. From Fig. 4(a), the high volume fraction of hcp phase (36\%) compared to deformation twins $(4.5 \%)$ reveals that for alloy I, fcc to hcp phase transformation is dominant. Two different hep variants can be identified. Figure 4(b) shows the corresponding inverse pole figure (IPF) map blended with the image quality (IQ) map. In Fig. 4(c), the kernel average misorientation (KAM) map with the first-nearest neighbor is shown. KAM value is commonly used as an approximate indicator of the density of geometry necessary dislocations (GND) [80,81]. The KAM map in Fig. 4(c) indicates that the boundary regions between fcc and hcp phases have a higher fraction of GND, while within the hcp phase region, the stress is uniformly released, as indicated by a low KAM value level. Figure 4(d) shows an overview of the TEM lamella obtained and the diffraction pattern in Fig. 4(e) from the dashed circle region in Fig. 4(d) reveals coexistence of hcp phase and deformation twins. The 

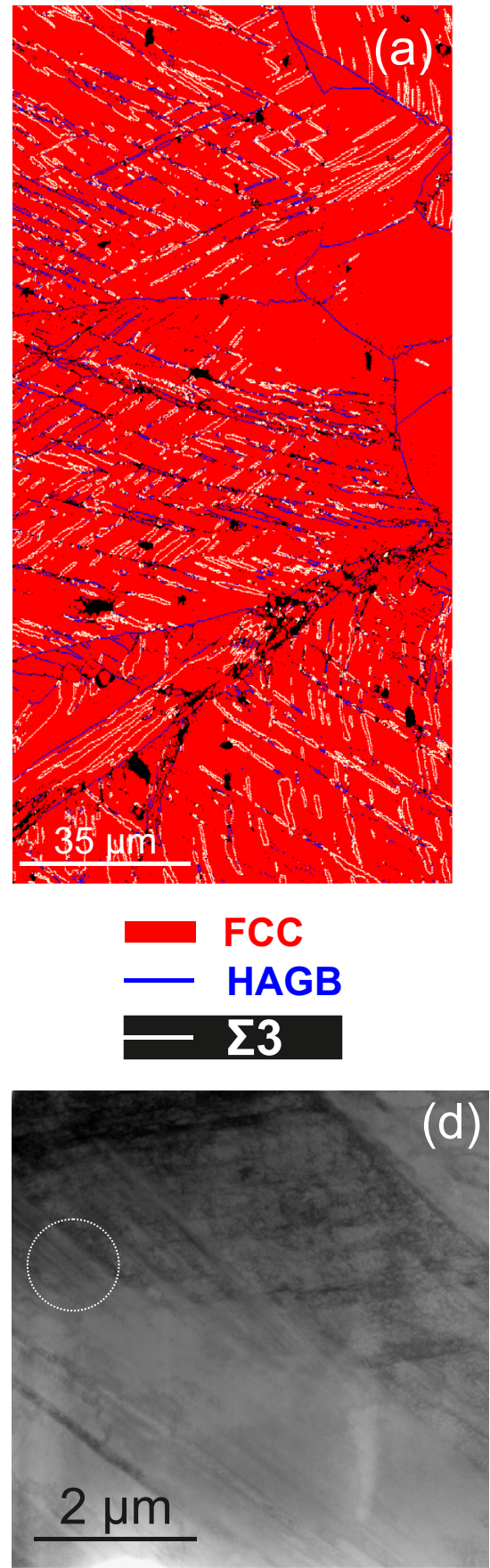
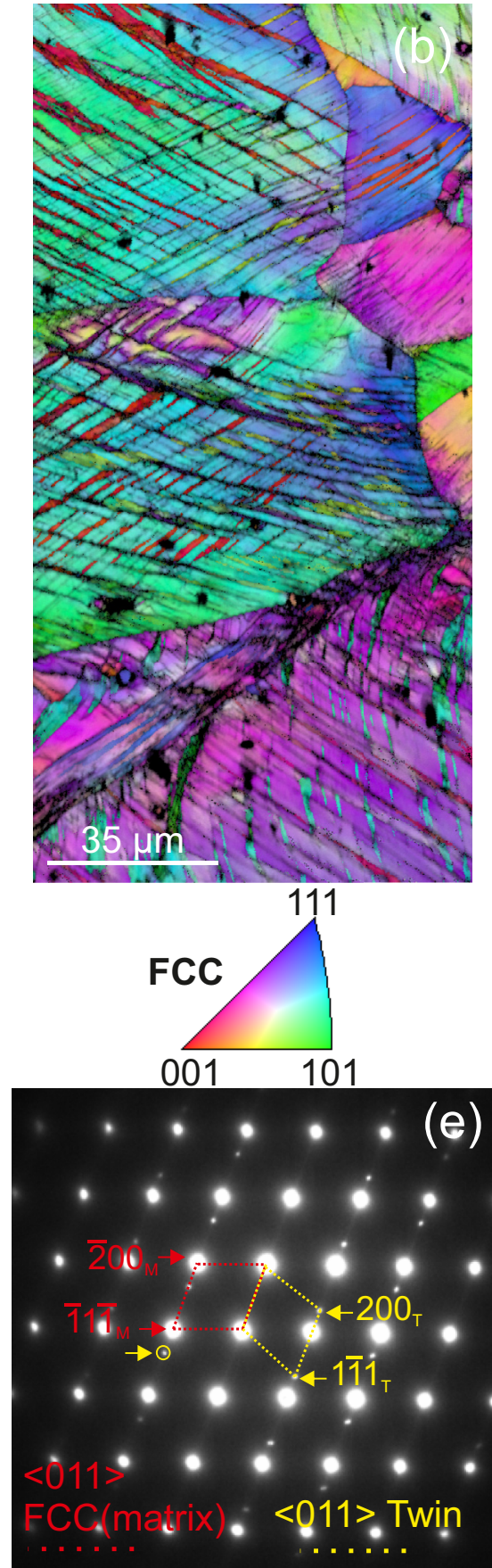
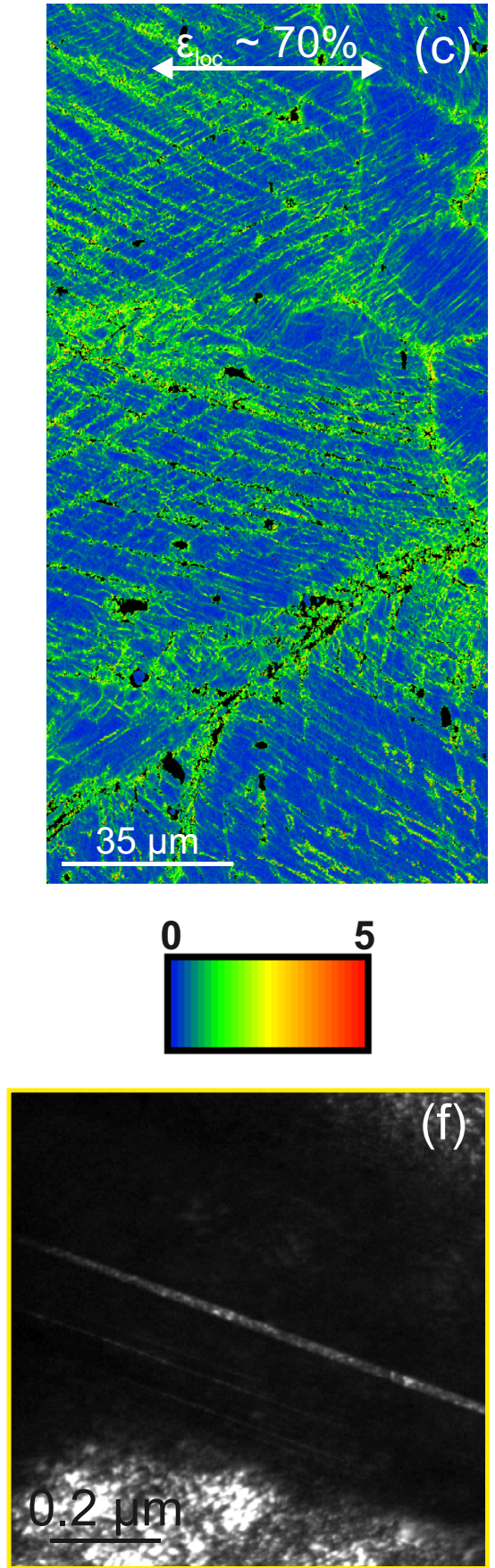

FIG. 6. EBSD and TEM analysis of alloy II $\left(\mathrm{Cr}_{20} \mathrm{Mn}_{30} \mathrm{Fe}_{24} \mathrm{Co}_{20} \mathrm{Ni}_{6}\right)$ at a local strain of $70 \%$. (a) Phase map showing the deformed area with intense twinning (colored in white) and no phase transformation. (b) IPF overlapped with IQ figure. (c) KAM map of first neighbor. (d) TEM overview of the lamella for analysis from the same region as in EBSD. (e) Diffraction pattern from dashed region in (d) showing the presence of deformation twins. (f) Dark-field image from the yellow circle in (e) highlighting nanotwins in the region.

deformation twins embedded in the fcc matrix are of nanosize, as shown in Fig. 4(e).

\section{Alloy II $\left(\mathrm{Cr}_{20} \mathrm{Mn}_{30} \mathrm{Fe}_{24} \mathrm{Co}_{20} \mathrm{Ni}_{6}\right)$}

Similarly, TEM characterization was carried out for alloy II. Figure 5 shows representative microstructures at a local strain of $20 \%$. Figure 5(a) exhibits an array of dislocations at $20 \%$ local strain, and a close-up in Fig. 5(b) reveals that dislocation pairs are narrowly spaced. Dislocation arrays normally indicate planar slip. Compared to alloy I, alloy II has much lower probability for generating deformation twins or stacking faults.

Combined EBSD and TEM analysis for alloy II were carried out for identification of dominant deformation mechanisms, as shown in Fig. 6. The phase map in Fig. 6(a) indicates that the deformed microstructure contains a single fcc phase and a high density of deformation twins at a local strain of $70 \%$. Two different variants of deformation twins can be identified, and no hcp phase is observed. Generation 

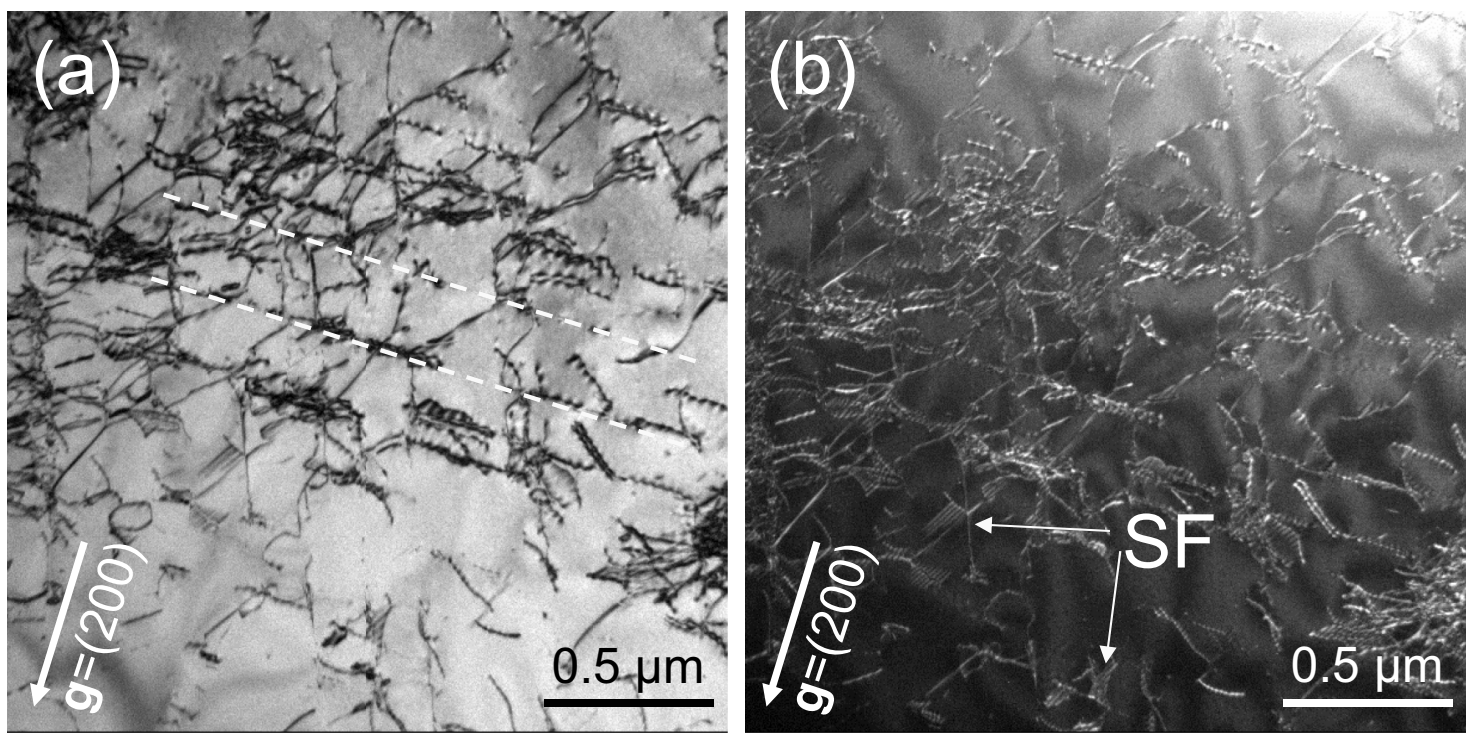

FIG. 7. TEM images showing typical microstructure of alloy III $\left(\mathrm{Cr}_{20} \mathrm{Mn}_{15} \mathrm{Fe}_{34} \mathrm{Co}_{20} \mathrm{Ni}_{11}\right)$ at a local strain of $\sim 30 \%$ under a $\mathbf{g}$ condition of (200). (a) TEM BF showing dislocations in a wavy mode and traces of planar slip. (b) TEM WBDF highlights the contrast of the same region as in (a) and the contrast of random SFs.

of deformation twins with different variants refines the grains, acting as dynamic Hall-Petch effect. Figure 6(b) shows the joint IPF and IQ maps revealing different orientations of the grains in this region. The KAM map in Fig. 6(c) shows that twin boundaries accumulate more dislocations compared to the grain interiors. TEM analysis in Figs. 6(d)-6(f) shows a high density of dislocations and deformation twins. The selected area diffraction pattern (SADP) in Fig. 6(e) confirms the generation of deformation twins with the satellite spots. By selecting diffraction spot of the twinning regions, as highlighted by the yellow circle in Fig. 6(e), the nanosized deformation twins are highlighted in the dark-field image in Fig. 6(f).

\section{E. Alloy III $\left(\mathrm{Cr}_{20} \mathrm{Mn}_{15} \mathrm{Fe}_{34} \mathrm{Co}_{20} \mathrm{Ni}_{11}\right)$}

In alloy III, dislocation tangles were observed at the early deformation stage (30\% local strain) of tensile deformation as shown in Fig. 7, indicating a wavy slip mode. Some planar slip traces can still be observed as indicated by dashed lines in TEM BF (Fig. 7(a)]. WBDF images in Fig. 7(b) highlight the contrast of few randomly distributed SFs. The observation of dislocations tangling at this deformation stage also indicates that alloy III has a higher SFE compared to alloys I and II.

The EBSD phase map in Fig. 8(a) shows intense deformation twins $(23.4 \%)$ at a local strain around $80 \%$. A negligible small fraction of hcp phase $(1.4 \mathrm{vol} . \%)$ can be observed, as highlighted in the phase map. The twins at the lower-right part of Fig. 8(a) appears twisted, which indicates further accommodation of deformation. The KAM map in Fig. 8(c) reveals an overall higher GND density compared to alloys I and II.

The intense twinning in alloy III is further shown by scanning/transmission electron microscopy (S/TEM) analysis in Fig. 8(d)-8(f). Figure 8(d) shows a TEM BF image taken from the same EBSD region as in Fig. 7. The thin and straight slices in the left part of the image are deformation twins in near edge-on condition. The twinning features are confirmed by the twin side spot in the SADP, right inset in Fig. 8(d). Figure $8(\mathrm{e})$ provides a clearer image showing regions of continuous twinning at a higher magnification in STEM mode. Figure 8(f) further displays one example of an edge-on deformation twin with around 16 atomic layers. Combined EBSD and TEM analysis in Fig. 8 reveals the dominant role of deformation twinning in alloy III.

\section{DISCUSSION}

Revealed by both ab initio calculation and the microstructural investigation, it is clear that magnetic ordering (disordered PM state vs ordered AFM state) plays a vital role in determining SFE and correspondingly the deformation mechanism. The $a b$ initio calculations in Fig. 1 clearly show the difference of the SFE for PM and AFM magnetic states. Alloy III has a lower magnetic critical temperature than the reference alloy $\left(\mathrm{Cr}_{20} \mathrm{Mn}_{20} \mathrm{Fe}_{34} \mathrm{Co}_{20} \mathrm{Ni}_{6}\right)$, alloy I $\left(\mathrm{Cr}_{20} \mathrm{Mn}_{24} \mathrm{Fe}_{30} \mathrm{Co}_{20} \mathrm{Ni}_{6}\right)$, and alloy II $\left(\mathrm{Cr}_{20} \mathrm{Mn}_{30} \mathrm{Fe}_{24} \mathrm{Co}_{20} \mathrm{Ni}_{6}\right)$. This implies that at ambient temperatures the behavior of alloy III could be more realistically modeled by assuming a PM state rather than an ordered magnetic AFM state. Hence, the SFEs of the alloys with compositions close to alloy III are more likely to follow the trend of the PM calculations shown in Fig. 1(a), in which alloy III also shows a higher SFE as compared to the reference $\mathrm{Cr}_{20} \mathrm{Mn}_{20} \mathrm{Fe}_{34} \mathrm{Co}_{20} \mathrm{Ni}_{6}$ alloy. This is consistent with the observation of dislocation tanging and intense deformation twinning observed in alloy III after tensile deformation.

Alloy II, in contrast, has a substantially higher magnetic critical temperature compared to the reference $\mathrm{Cr}_{20} \mathrm{Mn}_{20} \mathrm{Fe}_{34} \mathrm{Co}_{20} \mathrm{Ni}_{6}$ alloy as well as alloy I [Fig. 1(c) and Fig. 2]. This implies that, at room temperature, the behavior of alloy II may be more realistically modeled by an ordered 

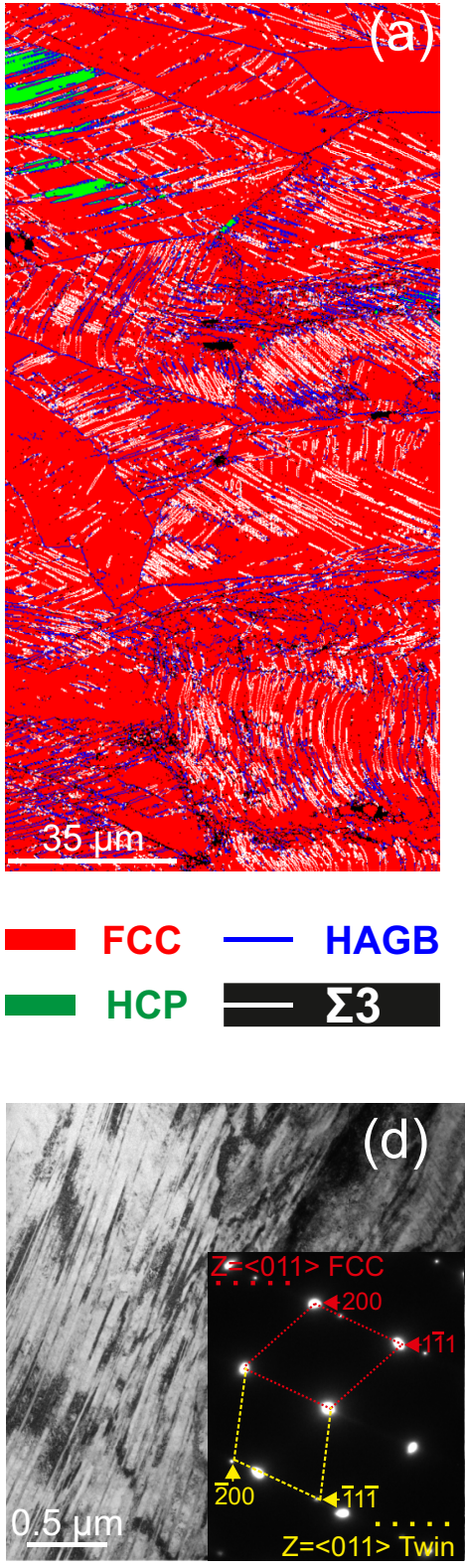
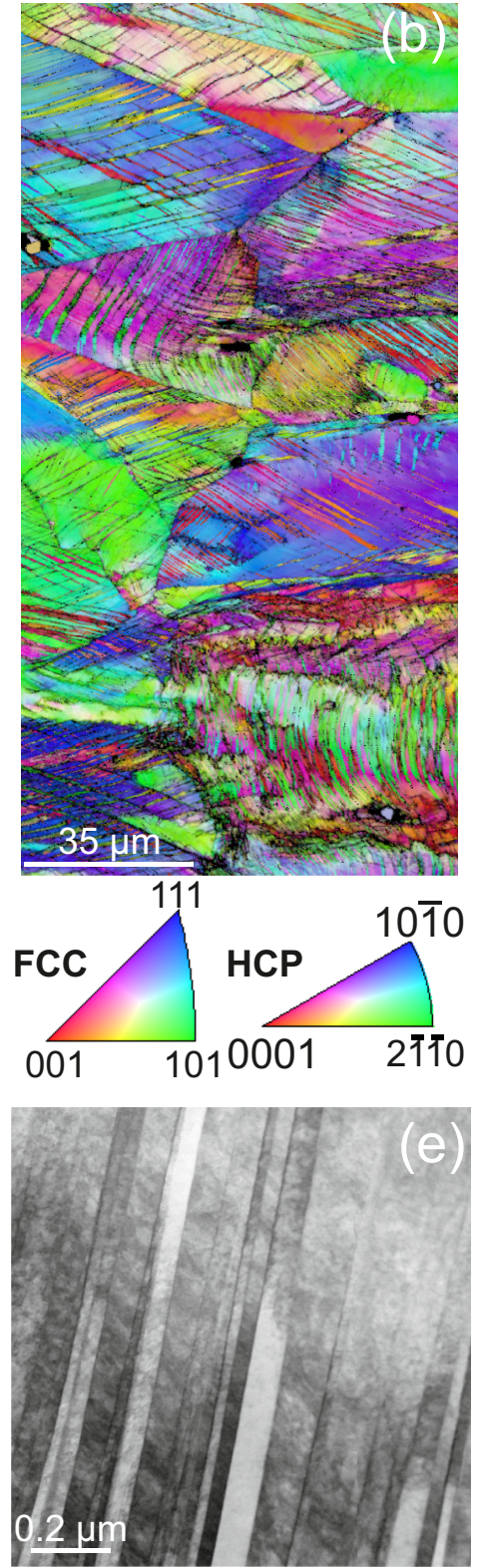
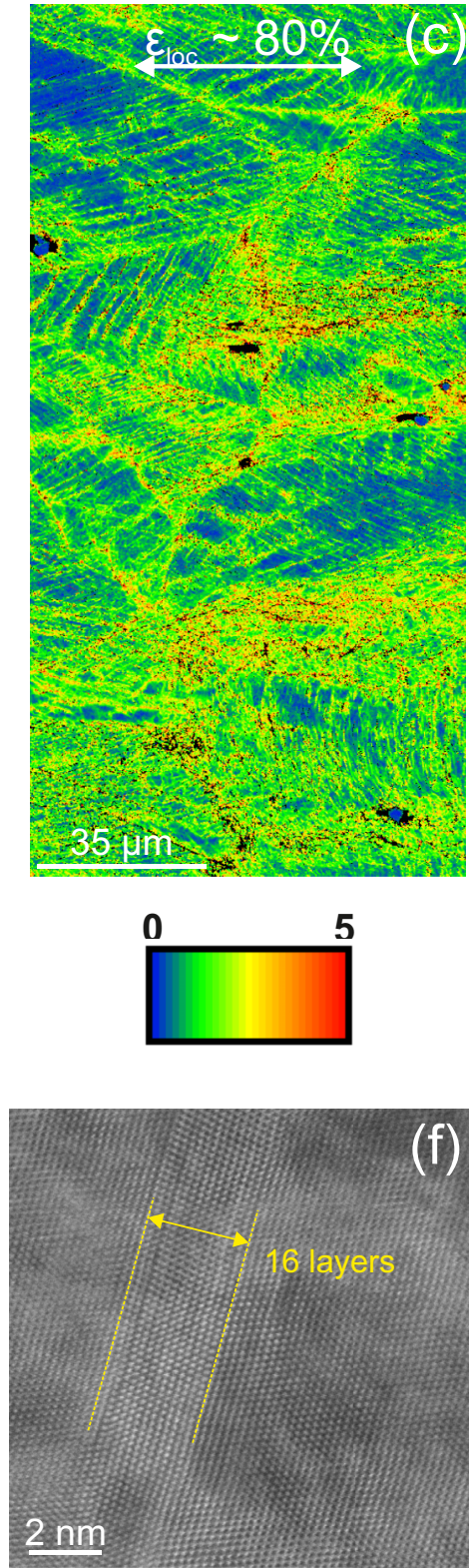

FIG. 8. EBSD and S/TEM analysis of alloy III $\left(\mathrm{Cr}_{20} \mathrm{Mn}_{15} \mathrm{Fe}_{34} \mathrm{Co}_{20} \mathrm{Ni}_{11}\right)$ at a local strain of $80 \%$. (a) Phase map showing the deformed area with a small fraction of hcp phase (colored in green) and intense twinning (colored in white). (b) IPF overlapped with IQ figure showing twisted twined region. (c) KAM map of first neighbor. (d) TEM overview showing a high density of twins with embedded SADP in the right corner. (e) STEM BF overview of the same region as in (a) at higher magnification. (f) STEM HAADF image showing an example of a deformation twin from (b) with around 16 atomic layers.

magnetic state rather than by an idealized PM state. The SFEs of the alloys with compositions close to that of alloy II then follow the trend shown in Fig. 1(b), in which alloy II is higher in the SFE than the reference $\mathrm{Cr}_{20} \mathrm{Mn}_{20} \mathrm{Fe}_{34} \mathrm{Co}_{20} \mathrm{Ni}_{6}$ alloy. This is, again, consistent with the observation in the present experiments that alloy II shows TWIP rather than TRIP.

Alloys I and II, as well as the reference TWIP alloy $\mathrm{Cr}_{20} \mathrm{Mn}_{20} \mathrm{Fe}_{34} \mathrm{Co}_{20} \mathrm{Ni}_{6}$, have the same concentrations of $\mathrm{Cr}$, $\mathrm{Co}$, and $\mathrm{Ni}$, but vary in $\mathrm{Mn}$ contents. The role of $\mathrm{Mn}$, specifically regarding its influence on magnetism, has been investigated in several other alloy classes. For example, in shape-memory alloys, Mn plays a special role in changing both the starting temperature for martensitic transformation and the Néel temperature [82-85]. In these cases, an increasing Mn content can simultaneously decrease the starting temperature for martensitic transformation and increase the Néel temperature, thus stabilizing the fcc austenite. This trend is also consistent with those shown in other HEA systems such as quaternary [86] and ternary alloys [30]. In the present case, as shown in Figs. 1 and 2, a higher Mn content in alloy II increases the critical magnetic temperature as compared to alloy I and alloy III by stabilizing an AFM state. The interplay between magnetism and phase stability alters correspondingly the SFE of the alloys. The different deformation modes for the three alloys manifest in return the differences in their SFEs, which is due to the influence of the magnetic properties. 
For non-Mn-containing HEAs, it has been found that the VEC correlates rather well with the phase (meta-)stability and consequently also with the prevalent deformation mechanism. Guo et al. [31] found that for $3 d$ transition-element-based HEAs without $\mathrm{Mn}$, the fcc phase is stable when VEC $\gtrsim 8$ and that the bcc phase appears for lower VEC. Chen et al. [32] confirmed similar trends for CrFeCoNi-based HEAs with $\mathrm{Al}$, $\mathrm{Cu}$, and Mo but again without Mn. Fang et al. [33] have found that $\mathrm{CrFeCoNi}$-based HEAs without $\mathrm{Mn}$ are prone to show TRIP when $\mathrm{VEC} \approx 8$ due to the metastability of the fcc phase. These trends are, however, not observed for Mn-containing HEAs, as pointed out in Refs. [31,33] and also in the present work. The present three Mn-containing HEAs confirm that the correlation between VEC and TRIP probability is weak. While all the three investigated HEAs have VECs below 7.9, only alloy I is TRIP dominant, and the other two alloys still show a stable fcc phase. Alloy II $\left(\mathrm{Cr}_{20} \mathrm{Mn}_{30} \mathrm{Fe}_{24} \mathrm{Co}_{20} \mathrm{Ni}_{6}\right)$ shows TWIP rather than TRIP, albeit alloy II has a lower VEC than the reference alloy. As described above, this unexpected behavior of Mn-including HEAs can be likely attributed to the impact of $\mathrm{Mn}$ on the magnetic properties. The magnetic critical temperature increases with the increase of the Mn content [Fig. 1(c) and Fig. 2], which could result in a larger fraction of magnetically ordered configurations also at ambient temperatures. The delicate interplay between magnetism and phase stability for Mn-containing alloys therefore renders the reduction of phase stability and correspondingly the values of SFEs to a simple VEC descriptor difficult or even misleading. This finding hence suggests the crucial role in $a b$ initio calculations that are capable to capture such magnetic effects.

Grain size is also another important parameter which influences the probability of TRIP and TWIP. In low-SFE fcc alloys, the onset of the TWIP/TRIP behavior usually occurs at an earlier deformation stage for specimens with large grain sizes compared to those with smaller grain sizes [87-89], i.e., the grain size influences activation of TRIP/TWIP kinetically but it is not the determining factor for triggering TWIP/TRIP effect in the materials. Hence, grain size is not the essentially determining factor for the observed different deformation modes for the three alloys under investigation.

\section{SUMMARY AND CONCLUSIONS}

In summary, we screened a wide compositional space of potential TRIP/TWIP HEAs in a combined $a b$ initio and experimental study and demonstrated the impact of magnetic ordering on the SFEs and the corresponding deformation behavior in three nonequiatomic quinary Mn-containing HEAs (alloy I: $\mathrm{Cr}_{20} \mathrm{Mn}_{24} \mathrm{Fe}_{30} \mathrm{Co}_{20} \mathrm{Ni}_{6}$, alloy II: $\mathrm{Cr}_{20} \mathrm{Mn}_{30} \mathrm{Fe}_{24} \mathrm{Co}_{20} \mathrm{Ni}_{6}$, and alloy III: $\mathrm{Cr}_{20} \mathrm{Mn}_{15} \mathrm{Fe}_{34} \mathrm{Co}_{20} \mathrm{Ni}_{11}$ ). The different deformation modes were attributed to the emerging AFM configurations with increasing Mn content, with TWIP and TRIP successfully introduced into the designed alloys. We find that in these three alloys the stabilization of an AFM ordering is mainly governed by the Mn content, which changes the magnetic critical temperature and alters the stability of the fcc phase. The predicted change of the magnetic critical temperatures has been further validated by temperature-dependent magnetization measurements. It is also found that the VEC alone does not capture effects arising from magnetic coupling and is hence not sufficient to describe the phase stability in Mn-containing CCA/HEAs. These results reveal $a b$ initiobased alloy screening as a reliable approach for the efficient design of metallic materials.

\section{ACKNOWLEDGMENTS}

Financial support of the German Research Foundation (Deutsche Forschungsgemeinschaft, DFG) within the Priority Programme 2006 (Compositionally Complex Alloys-High Entropy Alloys) and NWO/STW (VIDI Grant No. 15707) is acknowledged. The authors would like to gratefully thank M. Nellessen, K. Angenendt, M. Adamek, and B. Breitbach at the Max-Planck-lnstitut für Eisenforschung for the kind support. The authors also thank Dr. D. Ponge and Dr. J. Su for intense discussion.
[1] Z. Li, F. Körmann, B. Grabowski, J. Neugebauer, and D. Raabe, $A b$ initio assisted design of quinary dual-phase high-entropy alloys with transformation-induced plasticity, Acta Mater. 136, 262 (2017).

[2] Z. Li, C. C. Tasan, K. G. Pradeep, and D. Raabe, A TRIPassisted dual-phase high-entropy alloy: Grain size and phase fraction effects on deformation behavior, Acta Mater. 131, 323 (2017).

[3] O. Bouaziz, S. Allain, C. P. Scott, P. Cugy, and D. Barbier, High manganese austenitic twinning induced plasticity steels: A review of the microstructure properties relationships, Curr. Opin. Solid State Mater. Sci. 15, 141 (2011).

[4] B. C. De Cooman, Y. Estrin, and S. K. Kim, Twinning-induced plasticity (TWIP) steels, Acta Mater. 142, 283 (2018).

[5] J.-K. Kim and B. C. De Cooman, Stacking fault energy and deformation mechanisms in Fe-xMn-0.6C-yAl TWIP steel, Mater. Sci. Eng. A 676, 216 (2016).

[6] H. Idrissi, L. Ryelandt, M. Veron, D. Schryvers, and P. J. Jacques, Is there a relationship between the stacking fault character and the activated mode of plasticity of Fe-Mn-based austenitic steels? Scr. Mater. 60, 941 (2009).

[7] H. Idrissi, K. Renard, D. Schryvers, and P. J. Jacques, TEM investigation of the formation mechanism of deformation twins in Fe-Mn-Si-Al TWIP steels, Philos. Mag. 93, 4378 (2013).

[8] S. L. Wong, M. Madivala, U. Prahl, F. Roters, and D. Raabe, A crystal plasticity model for twinning- and transformationinduced plasticity, Acta Mater. 118, 140 (2016).

[9] S. Allain, J.-P. Chateau, O. Bouaziz, S. Migot, and N. Guelton, Correlations between the calculated stacking fault energy and the plasticity mechanisms in $\mathrm{Fe}-\mathrm{Mn}-\mathrm{C}$ alloys, Mater. Sci. Eng. A 387-389, 158 (2004).

[10] G. B. Olson and M. Cohen, Kinetics of strain-induced martensitic nucleation, Metall. Trans. A 6, 791 (1975).

[11] G. B. Olson and M. Cohen, A general mechanism of martensitic nucleation: Part I. General concepts and the FCC $\rightarrow \mathrm{HCP}$ transformation, Metall. Trans. A 7, 1897 (1976).

[12] T.-H. Lee, E. Shin, C.-S. Oh, H.-Y. Ha, and S.-J. Kim, Correlation between stacking fault energy and deformation 
microstructure in high-interstitial-alloyed austenitic steels, Acta Mater. 58, 3173 (2010).

[13] J. H. Choi, M. C. Jo, H. Lee, A. Zargaran, T. Song, S. S. Sohn, N. J. Kim, and S. Lee, Cu addition effects on TRIP to TWIP transition and tensile property improvement of ultrahigh-strength austenitic high-Mn steels, Acta Mater. 166, 246 (2019).

[14] W. Lu, C. H. Liebscher, G. Dehm, D. Raabe, and Z. Li, Bidirectional transformation enables hierarchical nanolaminate dualphase high-entropy alloys, Adv. Mater. 30, 1804727 (2018).

[15] M. Wang, Z. Li, and D. Raabe, In-situ SEM observation of phase transformation and twinning mechanisms in an interstitial high-entropy alloy, Acta Mater. 147, 236 (2018).

[16] Z. Wang, W. Lu, D. Raabe, and Z. Li, On the mechanism of extraordinary strain hardening in an interstitial high-entropy alloy under cryogenic conditions, J. Alloys Compd. 781, 734 (2019).

[17] J. Su, X. Wu, D. Raabe, and Z. Li, Deformation-driven bidirectional transformation promotes bulk nanostructure formation in a metastable interstitial high entropy alloy, Acta Mater. 167, 23 (2019).

[18] J.-W. Yeh, S.-K. Chen, S.-J. Lin, J.-Y. Gan, T.-S. Chin, T.-T. Shun, C.-H. Tsau, and S.-Y. Chang, Nanostructured highentropy alloys with multiple principal elements: Novel alloy design concepts and outcomes, Adv. Eng. Mater. 6, 299 (2004).

[19] D. B. Miracle and O. N. Senkov, A critical review of high entropy alloys and related concepts, Acta Mater. 122, 448 (2017).

[20] Y. Zhang, T. T. Zuo, Z. Tang, M. C. Gao, K. A. Dahmen, P. K. Liaw, and Z. P. Lu, Microstructures and properties of highentropy alloys, Prog. Mater. Sci. 61, 1 (2014).

[21] Z. Li and D. Raabe, Strong and ductile non-equiatomic highentropy alloys: Design, processing, microstructure, and mechanical properties, JOM 69, 2099 (2017).

[22] B. Cantor, I. T. H. Chang, P. Knight, and A. J. B. Vincent, Microstructural development in equiatomic multicomponent alloys, Mater. Sci. Eng. A 375-377, 213 (2004).

[23] B. Gludovatz, A. Hohenwarter, D. Catoor, E. H. Chang, E. P. George, and R. O. Ritchie, A fracture-resistant high-entropy alloy for cryogenic applications, Science 345, 1153 (2014).

[24] F. Otto, A. Dlouhý, C. Somsen, H. Bei, G. Eggeler, and E. P. George, The influences of temperature and microstructure on the tensile properties of a $\mathrm{CoCrFeMnNi}$ high-entropy alloy, Acta Mater. 61, 5743 (2013).

[25] H. Luo, Z. Li, and D. Raabe, Hydrogen enhances strength and ductility of an equiatomic high-entropy alloy, Sci. Rep. 7, 9892 (2017).

[26] H. Luo, Z. Li, A. M. Mingers, and D. Raabe, Corrosion behavior of an equiatomic CoCrFeMnNi high-entropy alloy compared with 304 stainless steel in sulfuric acid solution, Corros. Sci. 134, 131 (2018).

[27] H. Luo, W. Lu, X. Fang, D. Ponge, Z. Li, and D. Raabe, Beating hydrogen with its own weapon: Nano-twin gradients enhance embrittlement resistance of a high-entropy alloy, Mater. Today. 21, 1003 (2018).

[28] E. I. Galindo-Nava and P. E. J. Rivera-Díaz-del-Castillo, Understanding martensite and twin formation in austenitic steels: A model describing TRIP and TWIP effects, Acta Mater. 128, 120 (2017).
[29] L. Rémy and A. Pineau, Twinning and strain-induced f.c.c. $\rightarrow$ h.c.p. transformation on the mechanical properties of $\mathrm{Co}-\mathrm{Ni}-\mathrm{Cr}-$ Mo alloys, Mater. Sci. Eng. 26, 123 (1976).

[30] C. Niu, C. R. LaRosa, J. Miao, M. J. Mills, and M. Ghazisaeidi, Magnetically-driven phase transformation strengthening in high entropy alloys, Nat. Commun. 9, 1363 (2018).

[31] S. Guo, C. Ng, J. Lu, and C. T. Liu, Effect of valence electron concentration on stability of fcc or bcc phase in high entropy alloys, J. Appl. Phys. 109, 103505 (2011).

[32] R. Chen, G. Qin, H. Zheng, L. Wang, Y. Su, Y. Chiu, H. Ding, J. Guo, and H. Fu, Composition design of high entropy alloys using the valence electron concentration to balance strength and ductility, Acta Mater. 144, 129 (2018).

[33] W. Fang, R. Chang, P. Ji, X. Zhang, B. Liu, X. Qu, and F. Yin, Transformation induced plasticity effects of a non-equal molar Co-Cr-Fe-Ni high entropy alloy system, Metals 8, 369 (2018).

[34] A. J. Zaddach, C. Niu, C. C. Koch, and D. L. Irving, Mechanical properties and stacking fault energies of $\mathrm{NiFeCrCoMn}$ highentropy alloy, JOM 65, 1780 (2013).

[35] S. Huang, W. Li, S. Lu, F. Tian, J. Shen, E. Holmström, and L. Vitos, Temperature dependent stacking fault energy of FeCrCoNiMn high entropy alloy, Scr. Mater. 108, 44 (2015).

[36] S. Zhao, G. M. Stocks, and Y. Zhang, Stacking fault energies of face-centered cubic concentrated solid solution alloys, Acta Mater. 134, 334 (2017).

[37] Z. Z. Zhang, H. Sheng, Z. Wang, B. Gludovatz, Z. Z. Zhang, E. P. George, Q. Yu, S. X. Mao, and R. O. Ritchie, Dislocation mechanisms and 3D twin architectures generate exceptional strength-ductility-toughness combination in CrCoNi mediumentropy alloy, Nat. Commun. 8, 14390 (2017).

[38] Y. Ikeda, F. Körmann, I. Tanaka, and J. Neugebauer, Impact of chemical fluctuations on stacking fault energies of $\mathrm{CrCoNi}$ and $\mathrm{CrMnFeCoNi}$ high entropy alloys from first principles, Entropy 20, 655 (2018).

[39] S. Huang, H. Huang, W. Li, D. Kim, S. Lu, X. Li, E. Holmström, S. K. Kwon, and L. Vitos, Twinning in metastable high-entropy alloys, Nat. Commun. 9, 2381 (2018).

[40] Y. Ikeda, B. Grabowski, and F. Körmann, Ab initio phase stabilities and mechanical properties of multicomponent alloys: A comprehensive review for high entropy alloys and compositionally complex alloys, Mater. Charact. 147, 464 (2019).

[41] S. Zhao, Y. Osetsky, G. M. Stocks, and Y. Zhang, Localenvironment dependence of stacking fault energies in concentrated solid-solution alloys, Npj Comput. Mater. 5, 13 (2019).

[42] L. Vitos, H. L. Skriver, B. Johansson, and J. Kollár, Application of the exact muffin-tin orbitals theory: The spherical cell approximation, Comput. Mater. Sci. 18, 24 (2000).

[43] L. Vitos, Total-energy method based on the exact muffin-tin orbitals theory, Phys. Rev. B 64, 014107 (2001).

[44] A. V Ruban and H. L. Skriver, Screened Coulomb interactions in metallic alloys. I. Universal screening in the atomic-sphere approximation, Phys. Rev. B 66, 024201 (2002).

[45] A. V Ruban, S. I. Simak, P. A. Korzhavyi, and H. L. Skriver, Screened Coulomb interactions in metallic alloys. II. Screening beyond the single-site and atomic-sphere approximations, Phys. Rev. B 66, 024202 (2002).

[46] L. Vitos, Computational Quantum Mechanics for Materials Engineers: The EMTO Method and Applications (Springer, London, 2007). 
[47] L. Vitos, J. Kollár, and H. L. Skriver, Full charge-density calculation of the surface energy of metals, Phys. Rev. B 49, 16694 (1994).

[48] L. Vitos, J. Kollár, and H. L. Skriver, Full charge-density scheme with a kinetic-energy correction: Application to ground-state properties of the $4 d$ metals, Phys. Rev. B 55, 13521 (1997).

[49] P. Soven, Coherent-potential model of substitutional disordered alloys, Phys. Rev. 156, 809 (1967).

[50] B. L. Gyorffy, Coherent-potential approximation for a nonoverlapping-muffin-tin-potential model of random substitutional alloys, Phys. Rev. B 5, 2382 (1972).

[51] L. Vitos, I. A. Abrikosov, and B. Johansson, Anisotropic Lattice Distortions in Random Alloys from First-Principles Theory, Phys. Rev. Lett. 87, 156401 (2001).

[52] J. P. Perdew, K. Burke, and M. Ernzerhof, Generalized Gradient Approximation Made Simple, Phys. Rev. Lett. 77, 3865 (1996).

[53] K. Jin, B. C. Sales, G. M. Stocks, G. D. Samolyuk, M. Daene, W. J. Weber, Y. Zhang, and H. Bei, Tailoring the physical properties of Ni-based single-phase equiatomic alloys by modifying the chemical complexity, Sci. Rep. 6, 20159 (2016).

[54] F. Körmann, D. Ma, D. D. Belyea, M. S. Lucas, C. W. Miller, B. Grabowski, and M. H. F. Sluiter, "Treasure maps" for magnetic high-entropy-alloys from theory and experiment, Appl. Phys. Lett. 107, 142404 (2015).

[55] D. Ma, B. Grabowski, F. Körmann, J. Neugebauer, and D. Raabe, $A b$ initio thermodynamics of the CoCrFeMnNi high entropy alloy: Importance of entropy contributions beyond the configurational one, Acta Mater. 100, 90 (2015).

[56] J. Staunton, B. L. Gyorffy, A. J. Pindor, G. M. Stocks, and H. Winter, The "disordered local moment" picture of itinerant magnetism at finite temperatures, J. Magn. Magn. Mater. 45, 15 (1984).

[57] B. L. Gyorffy, A. J. Pindor, J. Staunton, G. M. Stocks, and H. Winter, A first-principles theory of ferromagnetic phase transitions in metals, J. Phys. F Met. Phys. 15, 1337 (1985).

[58] Y. Ikeda, I. Tanaka, J. Neugebauer, and F. Körmann, Impact of interstitial $\mathrm{C}$ alloying on phase stability and stacking fault energy of the CrMnFeCoNi high-entropy alloy, Phys. Rev. Mater. 3, 113603 (2019).

[59] B. Dutta, Y. Ikeda, F. Körmann, and J. Neugebauer, Understanding the magnetic ordering in high entropy alloys: A firstprinciples study (unpublished).

[60] Z. Rao, B. Dutta, F. Körmann, D. Ponge, L. Li, J. He, L. Stephenson, L. Schäfer, K. Skokov, O. Gutfleisch, D. Raabe, and $\mathrm{Z}$. Li, Unveiling the mechanism of abnormal magnetic behavior of $\mathrm{FeNiCoMnCu}$ high-entropy alloys through a joint experimental-theoretical study, Phys. Rev. Mater. 4, 014402 (2020).

[61] P. J. H. Denteneer and W. van Haeringen, Stacking-fault energies in semiconductors from first-principles calculations, J. Phys. C Solid State Phys. 20, L883 (1987).

[62] X. Zhang, B. Grabowski, F. Körmann, A. V Ruban, Y. Gong, R. C. Reed, T. Hickel, and J. Neugebauer, Temperature dependence of the stacking-fault Gibbs energy for $\mathrm{Al}, \mathrm{Cu}$, and $\mathrm{Ni}$, Phys. Rev. B 98, 224106 (2018).

[63] F. Birch, Finite elastic strain of cubic crystals, Phys. Rev. 71, 809 (1947)
[64] A. Otero-de-la-Roza and V. Luaña, GIBBS2: A new version of the quasi-harmonic model code. I. Robust treatment of the static data, Comput. Phys. Commun. 182, 1708 (2011).

[65] See Supplemental Material at http://link.aps.org/supplemental/ 10.1103/PhysRevMaterials.4.033601 for SFEs calculation and initial microstructure/mechanical investigations.

[66] C. L. Tracy, S. Park, D. R. Rittman, S. J. Zinkle, H. Bei, M. Lang, R. C. Ewing, and W. L. Mao, High pressure synthesis of a hexagonal close-packed phase of the high-entropy alloy CrMnFeCoNi, Nat. Commun. 8, 15634 (2017).

[67] F. Zhang, Y. Wu, H. Lou, Z. Zeng, V. B. Prakapenka, E. Greenberg, Y. Ren, J. Yan, J. S. Okasinski, X. Liu, Y. Liu, Q. Zeng, and Z. Lu, Polymorphism in a high-entropy alloy, Nat. Commun. 8, 15687 (2017).

[68] K. Sato, L. Bergqvist, J. Kudrnovský, P. H. Dederichs, O. Eriksson, I. Turek, B. Sanyal, G. Bouzerar, H. KatayamaYoshida, V. A. Dinh, T. Fukushima, H. Kizaki, and R. Zeller, First-principles theory of dilute magnetic semiconductors, Rev. Mod. Phys. 82, 1633 (2010).

[69] Z. Dong, S. Schönecker, W. Li, D. Chen, and L. Vitos, Thermal spin fluctuations in CoCrFeMnNi high entropy alloy, Sci. Rep. 8, 12211 (2018).

[70] Y. Ikeda, B. Grabowski, and F. Körmann, MPLTERN 0.3.0: Ternary plots as projections of MATPLOTLIB (2019), doi: 10.5281/zenodo.3528355.

[71] T. A. Caswell, M. Droettboom, J. Hunter, A. Lee, E. Firing, D. Stansby, J. Klymak, E. S. de Andrade, J. H. Nielsen, N. Varoquaux, T. Hoffmann, B. Root, P. Elson, R. May, D. Dale, J.-J. Lee, J. K. Seppänen, D. McDougall, A. Straw, P. Hobson, C. Gohlke, T. S. Yu, E. Ma, A. F. Vincent, S. Silvester, C. Moad, J. Katins, N. Kniazev, F. Ariza, and E. Ernest, MATPLOTLIB/MATPLOTLIB: REL: v3.1.1 (2019), doi: 10.5281/ zenodo.3264781.

[72] O. Grässel, L. Krüger, G. Frommeyer, and L. Meyer, High strength $\mathrm{Fe}-\mathrm{Mn}-(\mathrm{Al}, \mathrm{Si})$ TRIP/TWIP steels developmentproperties - application, Int. J. Plast. 16, 1391 (2000).

[73] S.-J. Lee, Y.-S. Jung, S.-I. Baik, Y.-W. Kim, M. Kang, W. Woo, and Y.-K. Lee, The effect of nitrogen on the stacking fault energy in $\mathrm{Fe}-15 \mathrm{Mn}-2 \mathrm{Cr}-0.6 \mathrm{C}-x \mathrm{~N}$ twinning-induced plasticity steels, Scr. Mater. 92, 23 (2014).

[74] Y. L. Gong, C. E. Wen, Y. C. Li, X. X. Wu, L. P. Cheng, X. C. Han, and X. K. Zhu, Simultaneously enhanced strength and ductility of $\mathrm{Cu}-x \mathrm{Ge}$ alloys through manipulating the stacking fault energy (SFE), Mater. Sci. Eng. A 569, 144 (2013).

[75] Y. T. Zhu, X. Z. Liao, and X. L. Wu, Deformation twinning in nanocrystalline materials, Prog. Mater. Sci. 57, 1 (2012).

[76] B. Mahato, S. K. Shee, T. Sahu, S. Ghosh Chowdhury, P. Sahu, D. A. Porter, and L. P. Karjalainen, An effective stacking fault energy viewpoint on the formation of extended defects and their contribution to strain hardening in a $\mathrm{Fe}-\mathrm{Mn}-\mathrm{Si}-\mathrm{Al}$ twinninginduced plasticity steel, Acta Mater. 86, 69 (2015).

[77] B. Mahato, T. Sahu, S. K. Shee, P. Sahu, T. Sawaguchi, J. Kömi, and L. P. Karjalainen, Simultaneous twinning nucleation mechanisms in an $\mathrm{Fe}-\mathrm{Mn}-\mathrm{Si}-\mathrm{Al}$ twinning induced plasticity steel, Acta Mater. 132, 264 (2017).

[78] J.-K. Kim, M.-H. Kwon, and B. C. De Cooman, On the deformation twinning mechanisms in twinning-induced plasticity steel, Acta Mater. 141, 444 (2017). 
[79] Z. Cheng, H. Zhou, Q. Lu, H. Gao, and L. Lu, Extra strengthening and work hardening in gradient nanotwinned metals, Science 362, eaau1925 (2018).

[80] M. Calcagnotto, D. Ponge, E. Demir, and D. Raabe, Orientation gradients and geometrically necessary dislocations in ultrafine grained dual-phase steels studied by 2D and 3D EBSD, Mater. Sci. Eng. A 527, 2738 (2010).

[81] J. Su, D. Raabe, and Z. Li, Hierarchical microstructure design to tune the mechanical behavior of an interstitial TRIP-TWIP high-entropy alloy, Acta Mater. 163, 40 (2019).

[82] H. Otsuka, H. Yamada, T. Maruyama, H. Tanahashi, S. Matsuda, and M. Murakami, Effects of alloying additions on Fe-Mn-Si shape memory alloys, ISIJ Int. 30, 674 (1990).

[83] B. Jiang, X. Qi, S. Yang, W. Zhou, and T. Y. Hsu (Xu Zuyao), Effect of stacking fault probability on $\gamma-\varepsilon$ martensitic transformation and shape memory effect in Fe-Mn-Si based alloys, Acta Mater. 46, 501 (1998).

[84] P. La Roca, P. Marinelli, A. Baruj, M. Sade, and A. Fernández Guillermet, Composition dependence of the Néel temperature and the entropy of the magnetic transition in the fcc phase of Fe-Mn and Fe-Mn-Co alloys, J. Alloys Compd. 688, 594 (2016).

[85] X. Wu and T. Y. Hsu (Xu Zuyao), Effect of the Neel temperature, $T_{\mathrm{N}}$, on martensitic transformation in Fe-Mn-Si-based shape memory alloys, Mater. Charact. 45, 137 (2000).

[86] Z. Li, K. G. Pradeep, Y. Deng, D. Raabe, and C. C. Tasan, Metastable high-entropy dual-phase alloys overcome the strength-ductility trade-off, Nature 534, 227 (2016).

[87] I. Gutierrez-Urrutia, S. Zaefferer, and D. Raabe, The effect of grain size and grain orientation on deformation twinning in a Fe-22wt.\% Mn-0.6wt.\% C TWIP steel, Mater. Sci. Eng. A 527, 3552 (2010).

[88] G. Dini, A. Najafizadeh, R. Ueji, and S. M. Monir-Vaghefi, Tensile deformation behavior of high manganese austenitic steel: The role of grain size, Mater. Des. 31, 3395 (2010).

[89] K. M. Rahman, V. A. Vorontsov, and D. Dye, The effect of grain size on the twin initiation stress in a TWIP steel, Acta Mater. 89, 247 (2015). 